\title{
A regional climate simulation over the Iberian Peninsula for the last millennium
}

\author{
J. J. Gómez-Navarro ${ }^{1}$, J. P. Montávez ${ }^{1}$, S. Jerez ${ }^{1}$, P. Jiménez-Guerrero ${ }^{1}$, R. Lorente-Plazas ${ }^{1}$, J. F. González-Rouco ${ }^{2}$, \\ and E. Zorita ${ }^{3}$ \\ ${ }^{1}$ Departamento de Física, Universidad de Murcia, Murcia, Spain \\ ${ }^{2}$ Departamento de Astrofísica y CC. de la Atmósfera, Universidad Complutense de Madrid, Madrid, Spain \\ ${ }^{3}$ Helmholtz-Zentrum Geesthacht, Geesthacht, Germany
}

Received: 27 September 2010 - Published in Clim. Past Discuss.: 8 October 2010

Revised: 20 March 2011 - Accepted: 21 March 2011 - Published: 29 April 2011

\begin{abstract}
A high-resolution $(30 \mathrm{~km})$ regional paleoclimate simulation of the last millennium over the Iberian Peninsula (IP) is presented. The simulation was performed with a climate version of the mesoscale model MM5 driven by the global model ECHO-G. Both models were driven by the same reconstructions of several external forcing factors. The high spatial resolution of the regional model allows climatologists to realistically simulate many aspects of the climate in the IP, as compared to an observational data set in the reference period 1961-1990. Although the spatial-averaged values developed by the regional model are tightly driven by the boundary conditions, it is capable to develop a different realisation of the past climate at regional scales, especially in the high-frequency domain and for precipitation. This has to be considered when comparing the results of climate simulations versus proxy reconstructions. A preliminary comparison of the simulation results with reconstructions of temperature and precipitation over the IP shows good agreement in the warming trends in the last century of the simulation, although there are large disagreements in key periods such as the precipitation anomalies in the Maunder Minimum.
\end{abstract}

\section{Introduction}

In the last years considerable efforts have been devoted to the understanding of the natural variability and its role in the evolution of the climate in the last millennia (Bradley and Jones, 1993; Jones et al., 2001; Zorita et al., 2005; Mann et al., 2008; Swingedouw et al., 2010, among others). This has allowed climatologists to frame the short instrumental period

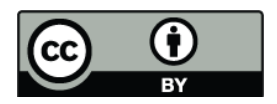

Correspondence to: J. P. Montávez (montavez@um.es) in a broader climatic context, and to understand some of the physical mechanisms responsible for the observed variability.

These efforts belong to two categories: climate reconstructions based on proxy indicators and climate model simulations. The former uses information from various indirect sources, including documentary records, tree rings, ice cores, etc. These sources provide information at various temporal resolutions about the past evolution of temperature and precipitation, among other variables (Bradley and Jones, 1993; Jones et al., 2001; Luterbacher et al., 2004; Mann et al., 2008). On the other hand, the use of comprehensive atmosphere ocean global circulation models (AOGCM) has become possible due to the impressive increase in computational power. This has allowed climatologists to perform simulations with state-of-the art global climate models over periods of several centuries (Zorita et al., 2005; Tett et al., 2007; Ammann et al., 2007; Swingedouw et al., 2010). Although the validation of these comprehensive models used for future climate projections can be performed by checking whether they are able to reproduce the main features of the actual climate, the reliability of climate models to realistically simulate climate changes is much more difficult to assess. The comparison of simulations of past climates with climate models with proxy-based climate reconstructions may thus increase the confidence put on future projections or identify drawbacks that should be corrected, thus improving the climate projections as well (González-Rouco et al., 2009).

However, this comparison is burdened by two important factors. On the one hand, climate reconstructions are based on data that is usually local or regional, whereas the present AOGCMs have a too coarse spatial resolution that precludes a realistic representation of the local features which may strongly influence proxy records. This may cause important

Published by Copernicus Publications on behalf of the European Geosciences Union. 
mismatches between simulations and reconstructions. For this reason, some of the comparison between model simulations and climate reconstructions over the past millennium performed so far have been limited to global or hemispheric scales (Jones et al., 2009). Several authors have also used a number of methodologies trying to overcome this problem. Stevens et al. (2008) grouped borehole temperature profiles into regional ensembles, to match the spatial resolution of the global AOGCM ECHO-G, of about $3.75^{\circ}$. These authors have, however, underlined the need for finer spatial resolution simulations. On the other hand, the climate system fluctuates internally over a large frequency range (Huybers and Curry, 2006). Climate models are also affected by this natural variability, and hence one should not expect a complete agreement at interannual timescales when comparing the temporal evolution of model simulations and reconstructions, even if both are perfect (Yoshimori et al., 2005).

Regarding the spatial scale gap between model and reconstructions, downscaling techniques are a common tool in meteorological and climate studies to address this problem. Driven by a AOGCM simulation, these techniques allow climatologists to take into account the effect of regional features, thus developing a more realistic climate for a limited area. In particular, dynamical downscaling methods involving the use of Regional Climate Models (RCM) solve similar equations as a AOGCM does, but using higher resolution for a limited area domain. The higher spatial resolution, which implements a more realistic orography, allows them to simulate some features of regional climates, like synoptic scale disturbances, more accurately than current AOGCMs, and for this reason RCMs are extensively employed in climate change projections within the context of large projects such as PRUDENCE or ENSEMBLES (Déqué et al., 2007; van der Linden and Mitchell, 2009, and references herein). Nevertheless, to date there are few studies where these models have been used for paleoclimate applications (Graham et al., 2009; Zorita et al., 2010), or only cover short periods of time farther back in the past (Hostetler et al., 2000; Renssen et al., 2001; Kjellström et al., 2010; Strandberg et al., 2011).

In this study, we present the first results of a simulation performed with the regional model MM5 driven by the global model ECHO-G over the last millennium (1001-1990) for a domain encompassing the Iberian Peninsula (IP). This area presents sharp spatial contrasts of mean temperature and precipitation due to its complex topography and to its location at the southern fringe of the North Atlantic storm tracks (FontTullot, 2000). Hence, it provides a good test bed to examine the skill of regional models in a paleoclimate context. For example, the precipitation in south-western part and the northern fringes of the IP is strongly influenced by the North Atlantic Oscillation, whereas precipitation along the Mediterranean coasts is much more weakly connected to the North Atlantic weather systems.

Although new climate reconstructions over diverse periods within the last millennium in the IP are being developed at this moment, to date there are only few available to compare against the simulations. In this study we focus on the gridded reconstructions of monthly, or seasonal, temperature and precipitation for the Western European region (Luterbacher et al., 2004; Pauling et al., 2006).

The paper is organised as follows: in Sect. 2 we describe the experiment setup of the AOGCM and the RCM, as well as the proxy reconstructions used for comparison with the simulations. We also describe some of the analysis tools employed in the paper. In Sect. 3 we evaluate the added value provided by MM5 to the climatology produced by ECHO-G for a reference period. For this purpose we use a simulation driven by meteorological reanalysis. In Sect. 4 we summarise the main features of the whole simulation, focusing on the differences between both models, and also compare the simulation with several proxy-based reconstructions for the area of study. Discussions and conclusions are given in Sect. 5.

\section{Description of simulations, data employed, and methodology}

For this study we have performed two simulations using different sets of driving conditions for a climate version of the regional model MM5. The first experiment (hereafter referred to as ERA40 + MM5) is driven by ERA40 reanalysis (Uppala et al., 2005) for the period 1961-1990. Jerez et al. (2010) have already shown that this simulation is capable of realistically reproducing the main features of the climate in the IP, in particular considering temperature. The second experiment (hereafter referred to as ECHO-G + MM5) has been driven by the global model ECHO-G, and covers the last millennium almost entirely (1001-1990). We use the climate simulated in the first experiment, together with an observational data base, to benchmark the skill of the regional model to reproduce the present climate when it is driven by ECHOG.

The ECHO-G global model driving the long RCM paleosimulation consists of the spectral atmospheric model ECHAM4 coupled to the ocean model HOPE-G (Legutke and Voss, 1999). The model ECHAM4 was used with a horizontal resolution $\mathrm{T} 30\left(\sim 3.75^{\circ} \times 3.75^{\circ}\right)$ and 19 vertical levels. The horizontal resolution of the ocean model is approximately $2.8^{\circ} \times 2.8^{\circ}$, with a grid refinement in the tropical regions and 20 vertical levels. A flux adjustment constant in time and with zero spatial average was applied to avoid climate drift. This adjustment is an integral part of the coupled atmosphere ocean model ECHO-G, and is an ad-hoc solution to avoid the unavoidable long-term climate drift that occurs when coupling two models with imperfect representation of surface fluxes. The model ECHO-G is included in the model suite of the Fourth Assessment Report of the Intergovernmental Panel on Climate Change. Although it has a relatively low-resolution atmosphere compared to the resolution 
of other IPCC models like ECHAM5-OM $\left(1.87^{\circ} \times 1.87^{\circ}\right)$ or HadCM3 $\left(2.75^{\circ} \times 3.75^{\circ}\right)$, assessments of the quality of the IPCC models measured by their skill to simulate the present observed climatology rank ECHO-G among the best IPCC models. Specifically, for the extratropical Northern Hemisphere atmospheric circulation, the study by Gleckler et al. (2008) places ECHO-G as the third best model. In terms of simulated precipitation, ECHO-G ranks as the seventh model despite its coarser resolution.

The GCM simulation was driven by estimations of three independent sources of external forcings: greenhouse gases (GHGs) concentrations in the atmosphere, total solar irradiance (TSI) and an estimation of the global mean radiative forcing of stratospheric volcanic aerosols. The latter two effects are included through the introduction of variations in an effective solar constant. Finally, it is important to note that although variations in land-use may have a strong impact in climate evolution, as clearly illustrated by Kleidon et al. (2000), this factor has not been included in the simulations. Land-use categories have been fixed to the present values, since to the author's knowledge there are no available reconstructions of this parameter for the last millenium over the Iberian Peninsula. Here we briefly discuss some general aspects of these forcings; for a full description of this simulation and their external forcings, the reader is referred to González-Rouco et al. (2003); Zorita et al. (2005) and references therein.

The evolution of the considered forcings is depicted in Fig. 1. The orange line represents the reconstruction employed for the variations of the TSI. Black lines show the estimated reduction in solar irradiance at the top of the atmosphere caused by volcanic eruptions. The sum of both lines is the effective solar constant that is implemented in the model to take into account both sources of external forcing. There is a series of maxima and minima in the TSI among which three minima around the years 1440, 1700, and 1810 stand out. These minima, which are remarked by grey bars in the figure, drive three respective minima in the near surface-air temperature (SAT) over the IP (see Fig. 11). These minima match known cold periods in the past, as further explained below. Finally, green, blue, and grey lines represent the evolution of nitrous oxide, carbon dioxide, and methane, respectively. GHGs concentrations show a relatively constant value until 1850 , roughly when the industrial period begins. Since then, all GHGs concentrations increase globally until the end of the simulated period in 1990. Both models, AOGCM and RCM, have been driven by identical external forcings to avoid physical inconsistencies.

The TSI reconstruction used in these simulations is described in Crowley (2000), and is based on ice core measurements of ${ }^{10} \mathrm{Be}$, residual ${ }^{14} \mathrm{C}$ from tree ring records and an estimate of ${ }^{14} \mathrm{C}$ from ${ }^{10} \mathrm{Be}$ fluctuations. The series includes information from solar spots observations from roughly 1700 onwards, which explains the high-frequency variability of the series in the last centuries. However, a

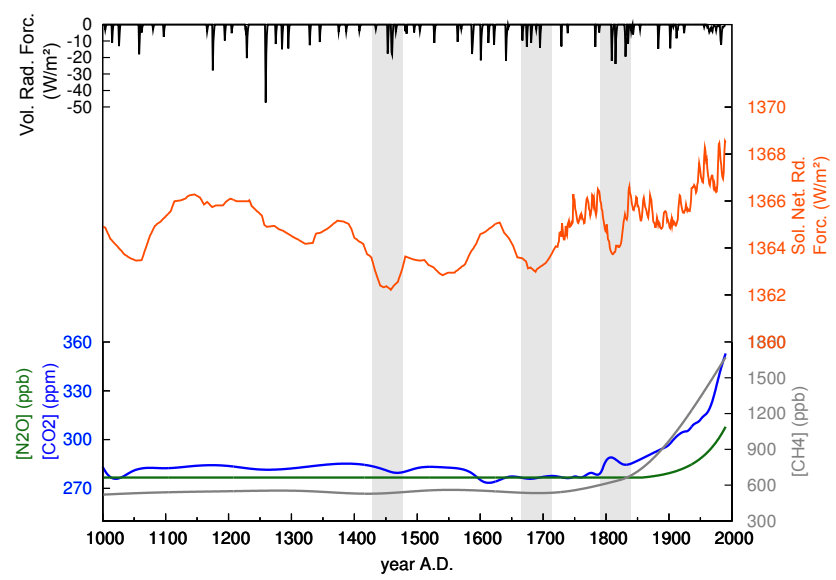

Fig. 1. Reconstruction of the forcings for the last millennium employed in the simulations (Crowley, 2000). Orange line is the reconstruction of the total solar irradiance. Black line shows the estimated reduction in the effective short wave radiative balance in the top of the atmosphere due to big volcano events. Blue, green, and grey lines show the evolution in the concentration of $\mathrm{CO}_{2}, \mathrm{NO}_{2}$, and $\mathrm{CH}_{4}$, respectively. Grey bars indicate three important periods further discussed in the sections below.

more recent reconstruction of this variable (e.g. Krivova et al., 2008), depicts a much smaller amplitude of the variance. In particular, these authors estimate a difference in total solar irradiance between the Late Maunder Minimum (a cold period around 1700) and late 20th century of $1.25 \mathrm{~W} \mathrm{~m}^{-2}$ (about $0.09 \%$ ), concurrently the past solar irradiance used in this simulation changes by $0.3 \%$. These authors indicate a much stronger change in the ultraviolet spectral band, with an increase of about 50\% since the Late Maunder Minimum. More recent simulations with the model ECHAM5-OM, which were driven by the reconstruction of TSI (i.e. without spectrally resolved changes) (Jungclaus et al., 2010) barely display a period of global lower temperatures similar to the Little Ice Age (LIA), distinct from the background internal variability. This apparent contradiction might be due to different reasons: the LIA might not have been a global phenomenon, the sensitivity of the real climate to changes in solar irradiance is higher than the model sensitivity, global temperatures are more strongly affected by variations in the ultraviolet band, or the Krivova et al. (2008) model to reconstruct total solar irradiance is not correct. At this stage, it is difficult to highlight one of these explanations as correct. At any rate, assuming that present climate models are broadly correct, a low-amplitude reconstruction of past solar irradiance and the existence of an externally-forced globalscale LIA does not seem to be compatible at this moment. However, it must be taken into account that this conclusion is limited due to the small number of simulations available to date.

The regional climate model used for the present study is a climate version of the Fifth-generation Pennsylvania-State 


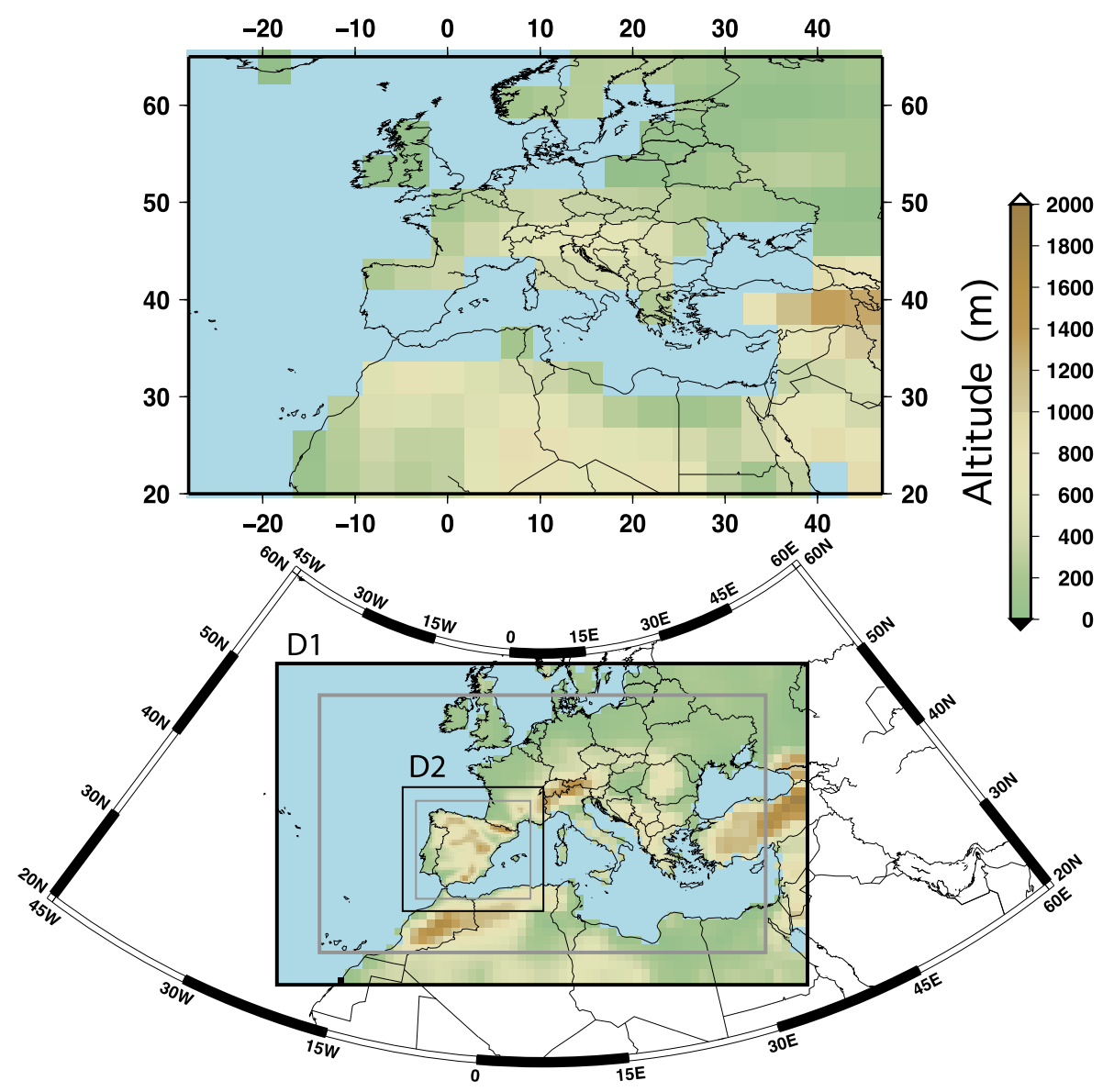

Fig. 2. Land-sea mask and orography of the AOGCM simulation (top) and spatial configuration of the two 2-way nested domains of 90 and $30 \mathrm{~km}$ respectively used in the RCM simulation (bottom). The colour of the squares in both figures represent the topography implemented in the models. Blue squares represent ocean grid boxes. Only the area inside the grey square in domain 2 (D2) is analysed hereafter.

University-National Center for Atmospheric Research Mesoscale Model (Dudhia, 1993; Grell et al., 1994; Montávez et al., 2006; Gómez-Navarro et al., 2010). Figure 2 depicts the spatial resolution implemented in the AOGCM (up) together with the two double-nested domains with a resolution of $90 \mathrm{~km}$ and $30 \mathrm{~km}$ respectively employed in the RCM simulation (down). The outer domain (D1) covers Europe and the Mediterranean Sea, since this area strongly influences the climate of the eastern part of the Iberian Peninsula (Font-Tullot, 2000). The inner domain (D2) covers the IP with higher resolution. The atmosphere is represented by 24 sigma levels in the vertical, with the top level at $100 \mathrm{hPa}$. The boundary conditions of the model ECHO-G are introduced into the outer domain of the RCM through a blending area of five grid points at the fringes of the outer domain, shown in grey squares in Fig. 2. This area is excluded from the analysis hereafter.

The physics configuration in the RCM has been chosen in order to minimise the computational cost, since none of the tested configurations provides the best performance for all kinds of synoptic events and regions (Fernández et al.,
2007). The physical options implemented here are: Grell cumulus parametrisation (Grell, 1993), Simple Ice for microphysics (Dudhia, 1989), Rapid Radiative Transfer Model radiation scheme (Mlawer et al., 1997), and the Medium Range Forecast parametrization for boundary layer (Hong and Pan, 1996). The Noah Land-Surface model (Chen and Dudhia, 2001a,b) has been used, as it simulates more accurately the climate in dry areas, especially in summer over most of the IP (Jerez et al., 2010). Boundary conditions for D1 are updated every $6 \mathrm{~h}$ in the ERA $40+$ MM5 experiment, and every $12 \mathrm{~h}$ in the ECHO-G + MM5 simulation.

In order to illustrate the added value provided by the model MM5, we compare the time series (mean value and variance) of the seasonal means from individual years of SAT and precipitation in a reference period (19611990 ) in the four data sets (ECHO-G, ERA40, ECHOG + MM5, and ERA40+MM5) with the European Climate Assessment \& Observations database (E-OBS) (Haylock et al., 2008). The E-OBS data set is a reconstruction of the evolution of SAT and precipitation for the recent past (1950 2006), which is the result of an interpolation of observational 
data to a high resolution regular grid $\left(0.25^{\circ} \times 0.25^{\circ}\right)$ that homogeneously covers Europe over land grid points. Specifically, we have used the third version of this data set. Although some problems regarding precipitation have been reported (Hofstra et al., 2009), we use this data base because it is commonly used for model validation purposes in large projects such as ENSEMBLES (van der Linden and Mitchell, 2009), and the daily temporal resolution of this data base allows the study of extreme events, which will be reported in future studies.

This comparison has been performed by means of Taylor diagrams (Taylor, 2001). These depict, in a polar coordinates graph, the correlation and variability ratio of two series. Instead of showing correlation and variability of two temporal series, as is the usual approach, the Taylor diagrams represent the spatial correlation and standard deviation ratio of two gridded spatial fields. To make all data sets comparable, the data of the four simulations have been spatially interpolated to the E-OBS grid, resulting in a total of 1209 grid cells over the IP after removing the ocean grid cells

In order to further evaluate similarities between the ECHO-G + MM5 and ERA40 + MM5 simulations, we have performed an Empirical Orthogonal Function (EOF) analysis of the seasonal series of SAT and precipitation. This methodology reduces the high dimensionality of these fields, deconstructing them into spatial patterns (EOFs) and associated principal components (PCs) (von Storch and Zwiers, 1999). By comparing the EOFs of both simulations we can gain some insight into the differences and similarities of their spatial correlation structure.

Finally, some preliminary comparisons against proxybased climatic reconstructions have been performed. We have employed the SAT reconstruction by Luterbacher et al. (2004) and the precipitation reconstruction by Pauling et al. (2006). Both data sets consist of monthly and seasonal series in a $0.5^{\circ} \times 0.5^{\circ}$ regular grid over Europe. They are based on a large variety of long instrumental series, on indices based on historical documentary evidence, and on natural proxies. These reconstructions have been performed with a Climate Field Reconstruction method. The reconstruction method is based on Principal Components (PC) regression, by which a multivariate statistical regression model is set up between the leading Principal Components of a gridded observational data set and the available proxy records. This statistical model is then used to reconstruct the temperature or precipitation Principal Components backwards in time and, by combining the reconstructed PCs with the spatial eigenvectors, the whole spatial field. We compare the seasonal mean series of SAT and precipitation in the model and in the reconstruction, but in both cases using only land points in their respective grids over the IP.

\section{Value added by the RCM}

This section aims to show the added value generated by the RCM with respect to the stand-alone AOGCM simulation. We compare the climatologies generated by MM5 when this regional model is driven by ECHO-G and ERA40 for a 30years reference period (1961-1990), respectively. Jerez et al. (2010) illustrated how the downscaling of ERA40 performed with MM5 is capable of reproducing the main features of the SAT of the IP, but no equivalent study for MM5 has been performed for precipitation so far. For this reason we have also compared the results of the simulations with the E-OBS data base, which contains information about SAT and precipitation.

\subsection{Mean values}

Figure 3 shows the mean value of the seasonal SAT for the reference period for all data sets. Each column depicts the result for each of the four models and the observational data set in this order: ECHO-G, ERA40, ECHO-G + MM5, ERA40 + MM5, and E-OBS. Each row represents the mean climatology broken down by season. The large difference between ECHO-G and ERA40 (first and second columns, respectively) stands out. This difference is attributable to their different spatial resolution (coarser in ECHO-G), the differences in the formulation of ECHO-G and the IFS model employed to develop ERA40, and to the fact that the reanalysis data incorporates the information from observations of the actual climate (Uppala et al., 2005). Due to this assimilation process, ERA40 is a more reliable realisation of the recent past. Comparing both data sets, ECHO-G tends to develop too cold summers and too warm winters, leading to an underestimation of the amplitude of the annual cycle. Furthermore, the spatial resolution of ECHO-G does not allow us to capture the orographic details of the IP (see Fig. 2). In particular, the model is not capable of realistically representing some characteristics of the south of the IP, since it is defined as ocean grid-cells.

On the other hand, columns 3 and 4 in Fig. 3 show the result of nesting MM5 into the former data sets. The similarities between these simulations are noticeable, and are also similar to the observations depicted in column 5 . The resolution of MM5 is able to take into account the main geographical characteristics of the IP, as can be noticed by the cold areas in both columns, which correspond quite well with the higher altitude regions (see Fig. 2). Important differences still remain, such as an underestimation up to $2{ }^{\circ} \mathrm{C}$ of the SAT in the southwestern parts of the IP in summer, and a similar magnitude of overestimation of winter SAT in the central region. This underestimation of the amplitude of the annual cycle seems to be predetermined by the driving AOGCM. Hence, although MM5 ameliorates this deficiency, it is not able to correct it completely. 


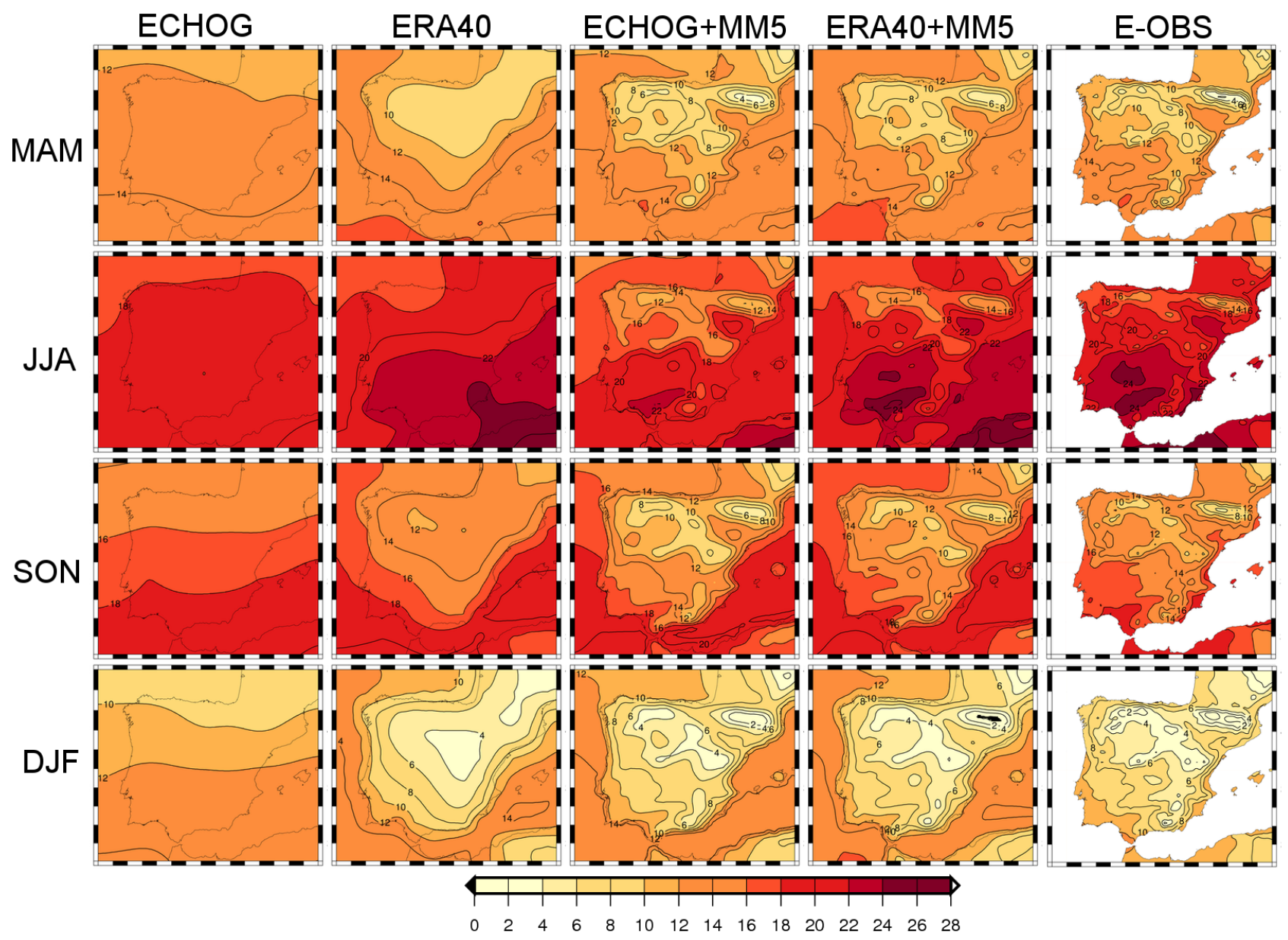

Fig. 3. Mean value of SAT (in ${ }^{\circ} \mathrm{C}$ ) in the period 1961-1990 for ECHO-G, ERA40, and MM5 nested to both (by columns) in all the seasons (by rows). Last column depicts the values for the E-OBS data base. All fields have been interpolated to a 7 min regular grid to ease the visual comparison.

A similar picture is found for precipitation (Fig. 4). ECHO-G and ERA40 develop different rainfall patterns (see columns 1 and 2). In general, ECHO-G underestimates the amount of precipitation, more notably in the wettest parts of the IP in the North, where the underestimation is up to $150 \mathrm{~mm} \mathrm{month}^{-1}$ in winter. This underestimation is stronger in winter and spring. The differences may be due to the coarser resolution of ECHO-G and its orography, which fails to discriminate between land and sea points at regional scale, but also to differences in the local and global circulation, as further discussed below. As in the case of SAT, MM5 tends to narrow these differences, as can be appreciated in columns 3 and 4 . In the case of precipitation there are nevertheless larger differences between the regional simulations. The main one is the overestimation of the precipitation in the ECHO-G + MM5 simulation in the Northwest of the IP in winter and autumn. Precipitation is underestimated in the south in warmer seasons.
As stated above, an important difference between ERA40 and the ECHO-G simulation is that the latter does not include assimilation of observations. Due to the internal variability of the AOGCM, some of the main circulation modes in the model may not be simultaneous with those observed in the actual climate. In the ERA40 reanalysis this temporal evolution matches the observed one, since it does include observational data assimilation. Thus, some of the differences in the ECHO-G + MM5 and ERA40 + MM5 simulations in the 30years period we have used as reference could be attributable directly to this cause, which is independent of the skill of the regional model. In particular, precipitation in the IP is known to be strongly influenced by NAO (Trigo et al., 2004), so differences in the state of this circulation mode in the reference period may explain part of the bias in the amounts of precipitation. Nevertheless, there are other important factors more directly related to the skill of the model, further commented on below. 


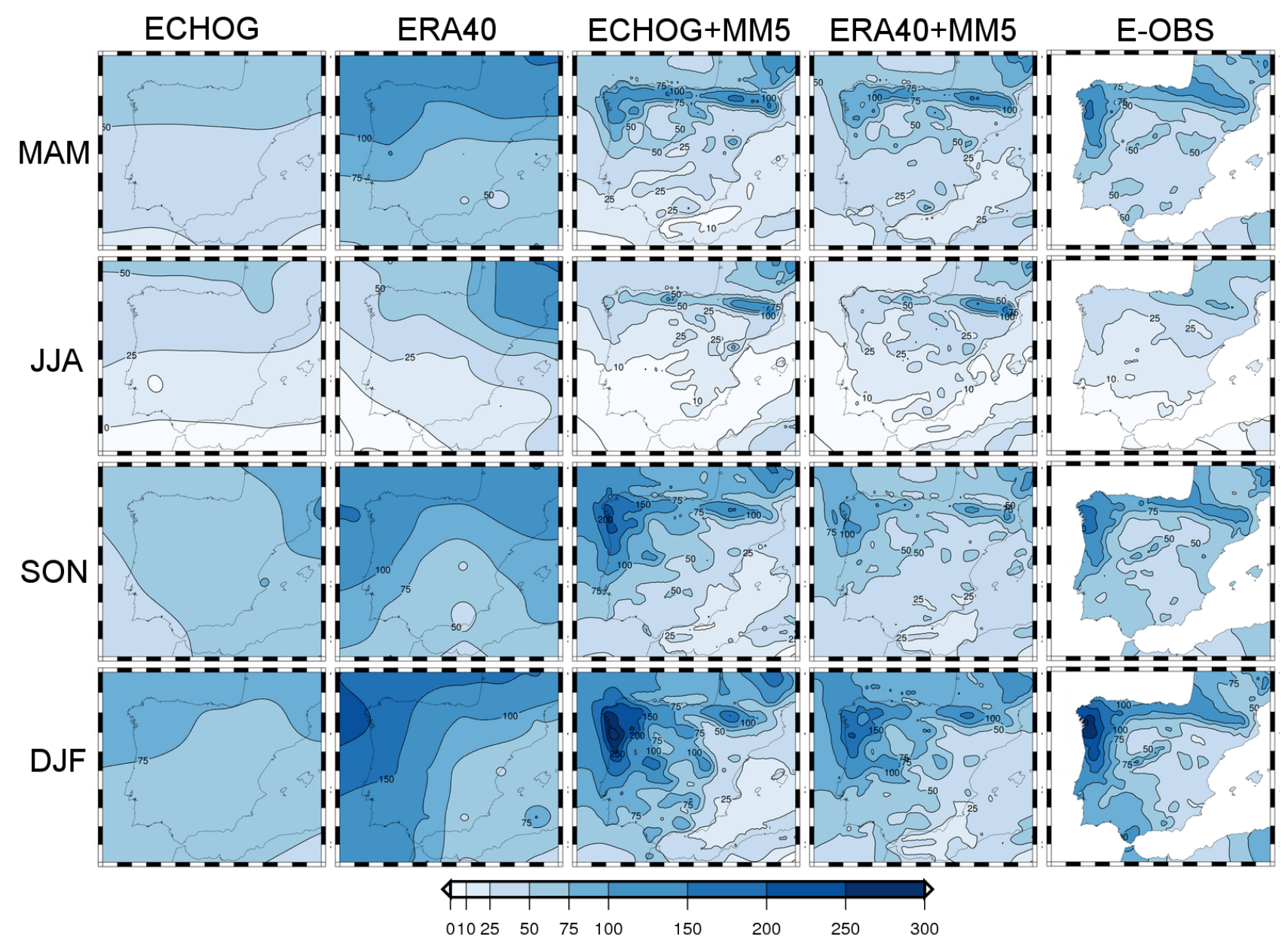

Fig. 4. Mean value of monthly precipitation (in mm month ${ }^{-1}$ ) in the period 1961-1990 for ECHO-G, ERA40, and MM5 nested to both (by columns) in all the seasons (by rows). Last column depicts the values for the E-OBS data base. All fields have been interpolated onto a 7-min regular grid to ease the visual comparison.

The improvement achieved by MM5 can be visualised in the Taylor diagrams (Fig. 5). In these diagrams we compare, by season, the performance of the four model integrations when reproducing the mean SAT and precipitation in the reference period compared to the E-OBS data base. In particular, each triangle in the figure depicts in polar coordinates the spatial correlation (angle) and standard deviation ratio (radius) between SAT mean values of each experiment and E-OBS. Similarly, each diamond represents the same calculation for precipitation. Climatologies of the four experiments have first been interpolated to the E-OBS grid to perform the calculations. ECHO-G underestimates SAT spatial variability in all seasons, as expected, due to its coarse resolution. ERA40 performs better in this respect, although it is still not able to represent the many variations in the climate over the IP. When the RCM is driven by both data sets, it simulates a very similar variability, which is also close to the observed. Although this may be partly due to the similar spatial resolution of the RCM simulations and the E-OBS data base, it is evident that the use of MM5 brings the global data sets closer to the observations. Regarding the correlation, MM5 simulates an SAT pattern in both experiments, which correlates 0.95 with the observed one for each season, further highlighting the added value of the regional model. For precipitation we find a more complex behaviour. As before, ECHO-G systematically underestimates the spatial variability due the its coarse resolution. The correlation with the observations is high in summer because it is able to reproduce the observed North-South gradient, but in other seasons it is very low. MM5 is able to improve both aspects, and the correlation between precipitation with observations is over 0.8 for all seasons. Correlation between precipitation in ERA40 and E-OBS is high in general, and thus MM5 is not able to improve this aspect very much. ERA40+MM5 shows, in general, lower spatial variability than ERA40, in some cases narrowing the differences between model and observations and in some others increasing them.

Summarising Figs. 3 to 5, MM5 is able to improve several aspects of the present climate simulated by ECHO-G. On one hand, it increases the amplitude of the SAT annual cycle, 

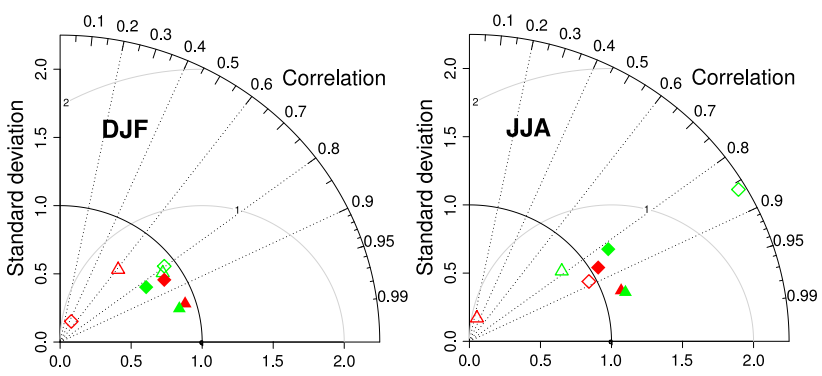

\subsection{Temporal variability}

We have also examined the effect of MM5 on the simulated interannual variability of SAT and precipitation. The standard deviations of the seasonal mean temporal series of SAT are shown in Fig. 6. As in Figs. 3, and 4, columns 1 and 2 show the results for ECHO-G and ERA40. The main difference between these patterns is the strong underestimation of the interannual variability in winter and autumn in ECHOG. Nevertheless, the underestimation is not constant across the four seasons, and in fact the variability in some areas of the North of the IP in summer and spring is overestimated with respect to ERA40. The corresponding simulations when MM5 is coupled to both data sets are shown in columns 3 and 4 of the same figure, and column 5 depicts the same data for the E-OBS data base. ECHO-G+MM5 systematically underestimates the SAT variability with respect to ERA40+MM5, and there are large differences in their spatial structure, the mismatch being more noticeable in spring. Nevertheless, the RCM is able to correct some of the main deficiencies of ECHO-G. For instance, it increases the interannual variability in autumn and winter, and decreases it in the North in summer, making the structure of the SAT variability more similar to the observations. Thus, the effect of MM5 is to correct ECHO-G by increasing and decreasing interannual variability, depending on the season and area, but in all cases narrowing differences between ECHO-G and ERA40, and reducing differences with respect to E-OBS.

Figure 7 depicts the same information regarding the interannual variability of the seasonal mean precipitation. As it could be expected, the wettest areas show a larger variability in every experiment. It is apparent that ECHO-G strongly underestimates the precipitation interannual variability in all seasons, more noticeably in summer (see columns 1 and 2). MM5 corrects some of these differences, increasing the variability in many areas. In particular, the pattern of precipitation variability is very similar in ECHO-G + MM5 and ERA40+ MM5 (see columns 3 and 4), although there exists some underestimation of the precipitation variability in the Northwest of the IP in the ECHOG + MM5 experiment, mainly in the wettest areas. This contrasts with the fact that this simulation develops stronger precipitation amounts than ERA40 + MM5 (Fig. 4). These larger precipitations, together with their less variability, may be attributable to deficiencies in ECHO-G in reproducing the weather types that affect the climate over the IP, as well as differences due to internal variability.

Summarising, ECHO-G tends to underestimate the regional interannual variability of the temporal series of SAT and precipitation over the IP in the reference period with respect to ERA40. MM5 is able to partly correct this drawback, with a general increase of interannual variability. Furthermore it also corrects the overestimation of SAT variability in the North of the IP in summer. The improvements introduced by the downscaling process may have an important 


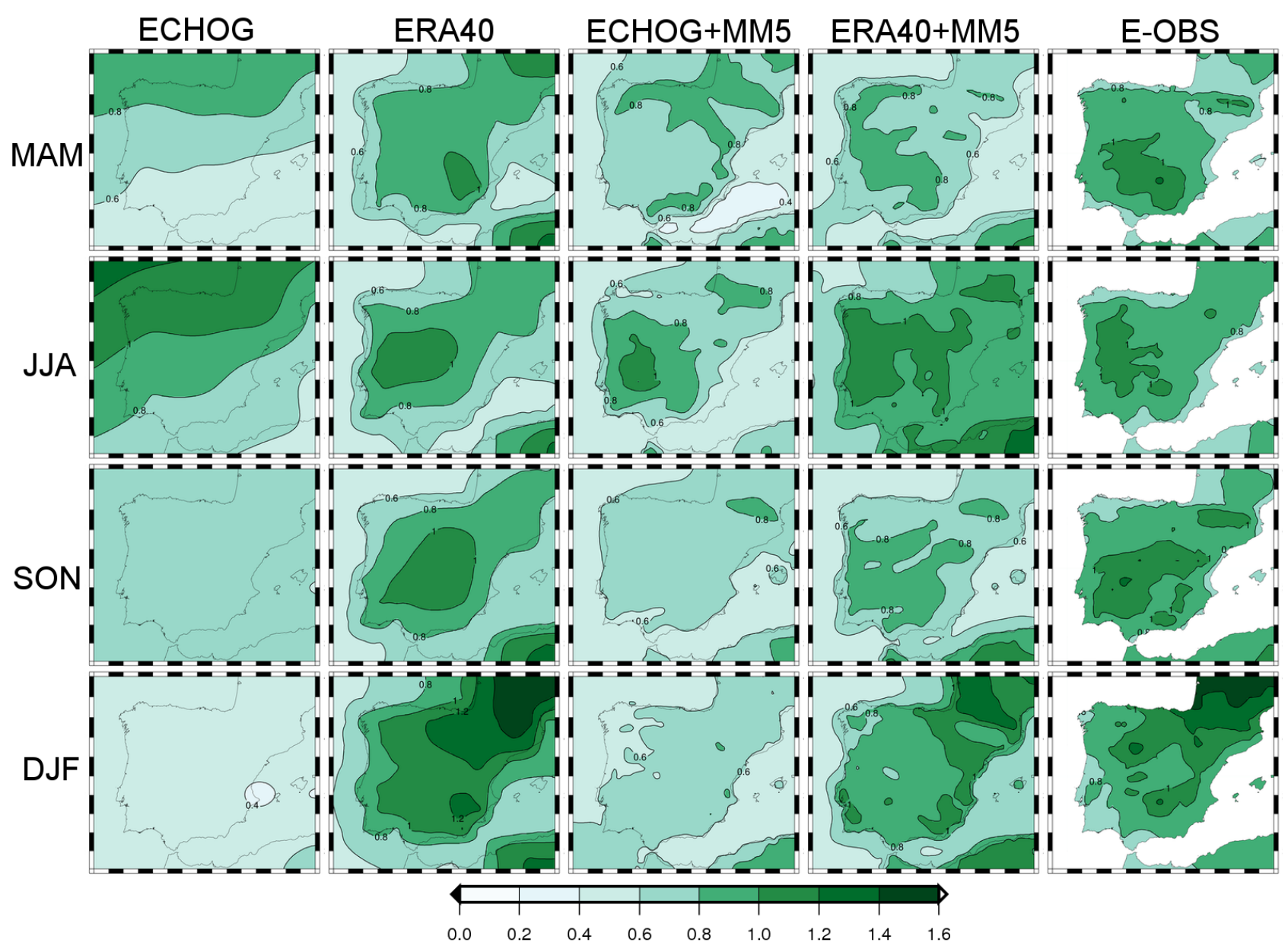

Fig. 6. Standard deviation (in ${ }^{\circ} \mathrm{C}$ ) of seasonal mean series of SAT in the period 1961-1990 for ECHO-G, ERA40, and MM5 nested to both (by columns) in all the seasons (by rows). Last column depicts the values for the E-OBS data base. All fields have been interpolated to a 7 min regular grid to ease the visual comparison.

impact on inter comparison exercises between proxy reconstruction and simulations, since the former are strongly influenced by local climate features which are better reproduced by the RCM. For instance, there are areas with great potential for proxy studies, such as the Pyrenees, and other mountain ranges in the Southeast of the peninsula, in which MM5 clearly outperforms ECHO-G. Hence, comparison studies between ECHO-G + MM5 and reconstructions offer better reliability than between those and the AOGCM alone.

\subsection{Main variability modes}

Finally, we have investigated the coherence of the covariance structure of temperature and precipitation in the regional experiments driven by ECHO-G and ERA40 by means of an Empirical Orthogonal Function (EOF) analysis. This technique has been applied to the seasonal series of SAT and precipitation in the period 1961-1990 only over land grid points. It is important to note that the spatial patterns in the figures below are dimensionless, as they have been normalised to unit spatial variance. Hence, comparing the patterns does not indicate the amplitude of variability in each experiment, but only the relative spatial distribution of the correlation among the grid-cells. The comparison of the actual variability of both simulations has been presented in Figs. 6 and 7.

Figure 8 depicts the first three EOF patterns of SAT. The ordering of the maps is as follows: columns 1 and 2 show the first EOF for ECHO-G + MM5 and ERA40 + MM5, respectively. The second EOF for ECHO-G + MM5 and ERA40 + MM5 are shown in columns 3 and 4. Finally, the third EOF is shown in columns 5 and 6. Each row includes a season, going from spring (first row) to winter (last row). The percentage of variance explained by each EOF is shown in Table 1. In both experiments and in all seasons, the percentage of variance explained by the first EOF is higher than $75 \%$. The associated patterns present the same sign over the IP, and their shape is similar in both simulations. In summer, the form of the patterns seems to be related to the distance 
Table 1. Percentage of variance explained by each EOF of the seasonal mean series of SAT.

\begin{tabular}{|c|c|c|c|c|c|c|}
\hline & \multicolumn{2}{|c|}{ EOF1 } & \multicolumn{2}{|c|}{ EOF2 } & \multicolumn{2}{|c|}{ EOF3 } \\
\hline & ECHO-G + MM5 & ERA40 + MM5 & ECHO-G + MM5 & ERA40 + MM5 & ECHO-G + MM5 & ERA40 + MM5 \\
\hline MAM & 82.06 & 76.18 & 7.97 & 11.63 & 4.79 & 5.98 \\
\hline JJA & 79.68 & 79.73 & 10.12 & 9.86 & 4.65 & 5.29 \\
\hline SON & 82.95 & 80.14 & 7.67 & 10.88 & 3.28 & 3.29 \\
\hline DJF & 79.21 & 88.56 & 7.32 & 6.91 & 3.28 & 3.29 \\
\hline
\end{tabular}

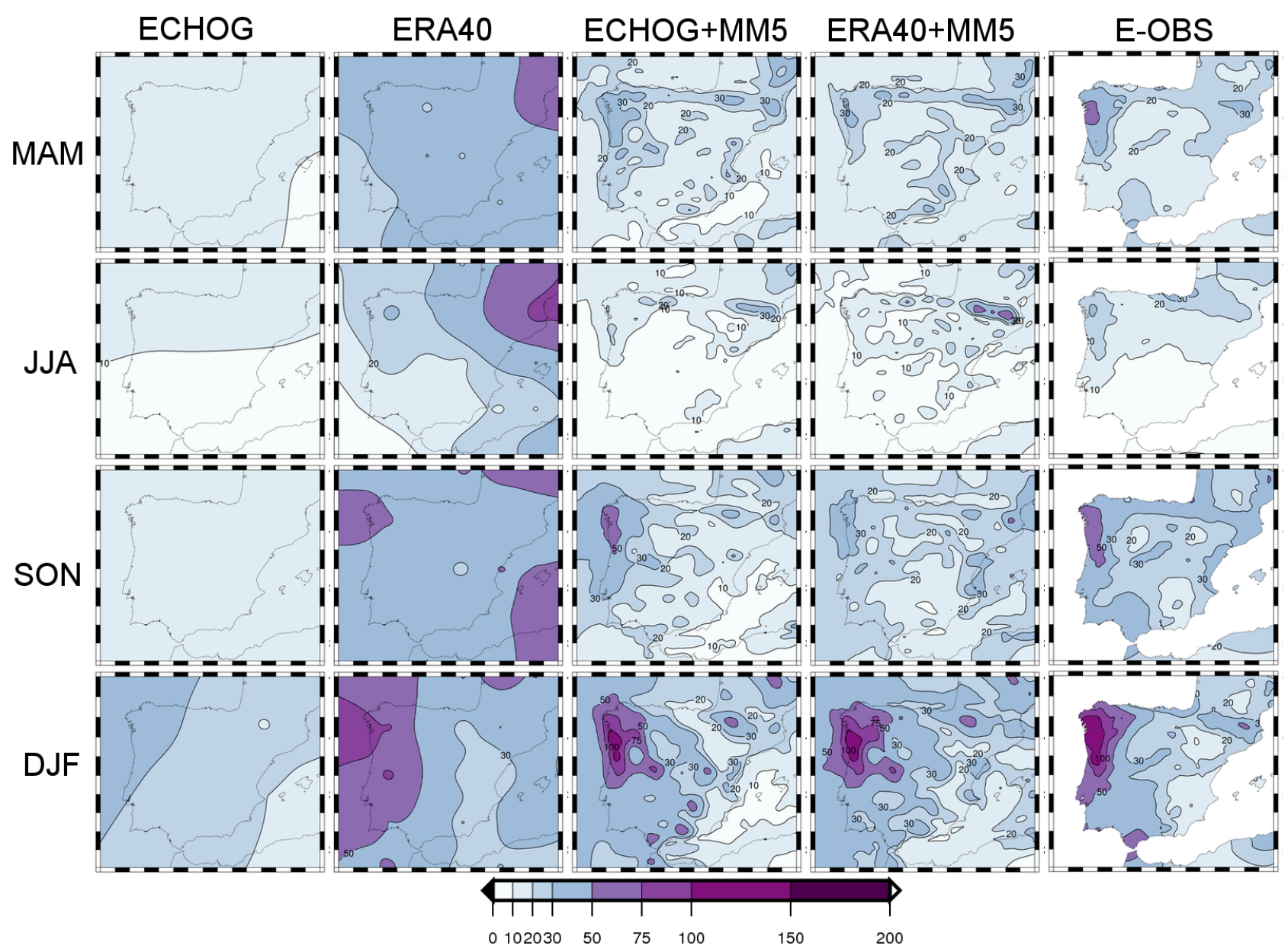

Fig. 7. Standard deviation (in mm month ${ }^{-1}$ ) of seasonal mean series of precipitation in the period 1961-1990 for ECHO-G, ERA40, and MM5 nested to both (by columns) in all the seasons (by rows). Last column depicts the values for the E-OBS data base. All fields have been interpolated onto a 7-min regular grid to ease the visual comparison.

to the ocean, whereas in autumn they are rather correlated to altitude. It is interesting to note that a similar annual cycle in the variability patterns has been found in an ensemble of climate change projections (Gómez-Navarro et al., 2010). There are nevertheless important differences between simulations. In winter ECHO-G + MM5 develops a North-South pattern which does not match the West-East pattern found in ERA40+ MM5 very well. The second and third EOFs explain much less percentage of variance in all cases, with similar amounts in both simulations. This supports the similarities between both simulations. The overall form of these patterns is in this case very similar. The largest differences are found in the third EOF patterns for winter, although the percentage of variance explained by these patterns is only around $3 \%$.

Figure 9 depicts the first three EOF patterns for precipitation. Table 2 shows the percentage of variance explained by each pattern. The percentage of variance explained by 
Table 2. Percentage of variance explained by each EOF of the seasonal mean series of precipitation.

\begin{tabular}{|c|c|c|c|c|c|c|}
\hline & \multicolumn{2}{|c|}{ EOF1 } & \multicolumn{2}{|c|}{ EOF2 } & \multicolumn{2}{|c|}{ EOF3 } \\
\hline & $\mathrm{ECHO}-\mathrm{G}+\mathrm{MM} 5$ & ERA40 + MM5 & ECHO-G + MM5 & ERA40 + MM5 & ECHO-G + MM5 & ERA40 + MM5 \\
\hline MAM & 45.70 & 40.27 & 18.16 & 19.84 & 10.67 & 9.99 \\
\hline JJA & 34.61 & 36.87 & 16.91 & 15.92 & 7.68 & 11.27 \\
\hline SON & 49.82 & 39.50 & 13.04 & 13.42 & 6.05 & 13.30 \\
\hline DJF & 74.07 & 69.65 & 8.29 & 11.04 & 5.25 & 5.21 \\
\hline
\end{tabular}

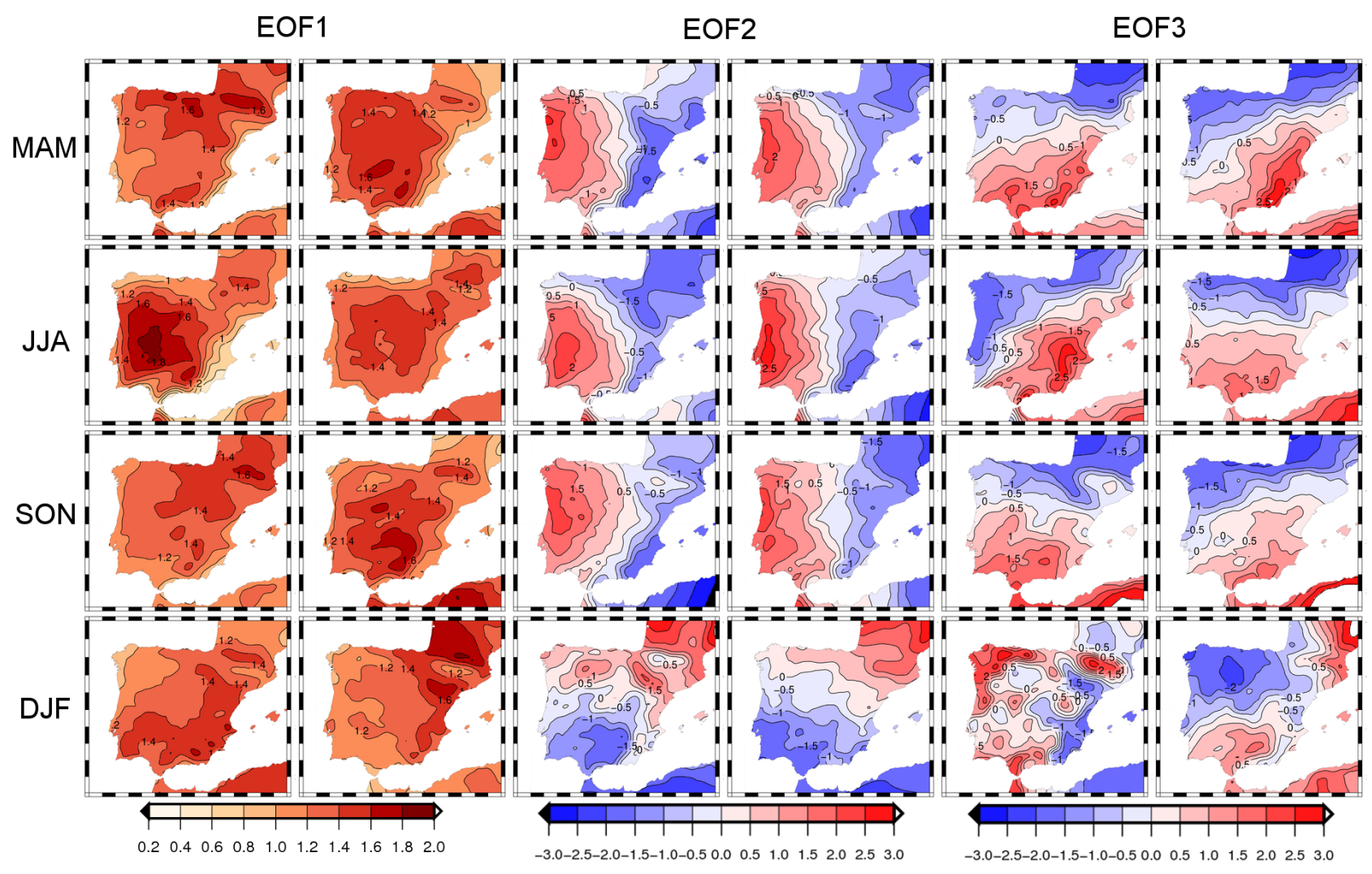

Fig. 8. Normalised EOF patterns obtained from the seasonal mean series of SAT for the period 1961-1990 in the simulations ECHOG+ MM5 and ERA40 + MM5.

the first EOF of precipitation is lower than for SAT. A prominent exception occurs in winter, for which the EOF explains a high percentage of variance, coherently in both experiments. Regarding the spatial structure of the leading EOF, it is pretty similar in both simulations, being more marked in the wettest areas in the North-West in coldest seasons and the higher altitude areas in the North-East of the IP in summer. There are nevertheless important differences in spring and in autumn. ECHO-G + MM5 tends to overestimate the intensity of the EOF pattern in the North-West, developing a pattern similar to that for winter. This difference could be explained again by the overestimation of the zonal circulation in ECHO-G. This stronger flow of humid air forces the RCM to simulate precipitation events in autumn that are not present when the
RCM is driven by ERA40. This may point to an unrealistic frequency of certain weather types in the ECHO-G simulation, which leads to a misrepresentation of the precipitation variability in ECHO-G + MM5 in the warmer seasons, and can also affect the SAT field. The second and third EOF are more relevant in this case, as they explain an important share of the variance. Their patterns are shown in columns 3 to 6 . There exists overall a good agreement between the two simulations.

The largest differences occur in summer, as ERA40 + MM5 tends to develop a more pronounced pattern in the high-altitude areas. Again, this difference can be attributed to the overestimation of the zonal flow in ECHO-G in this season, since the climate in the MM5 + ERA40 is more weakly 


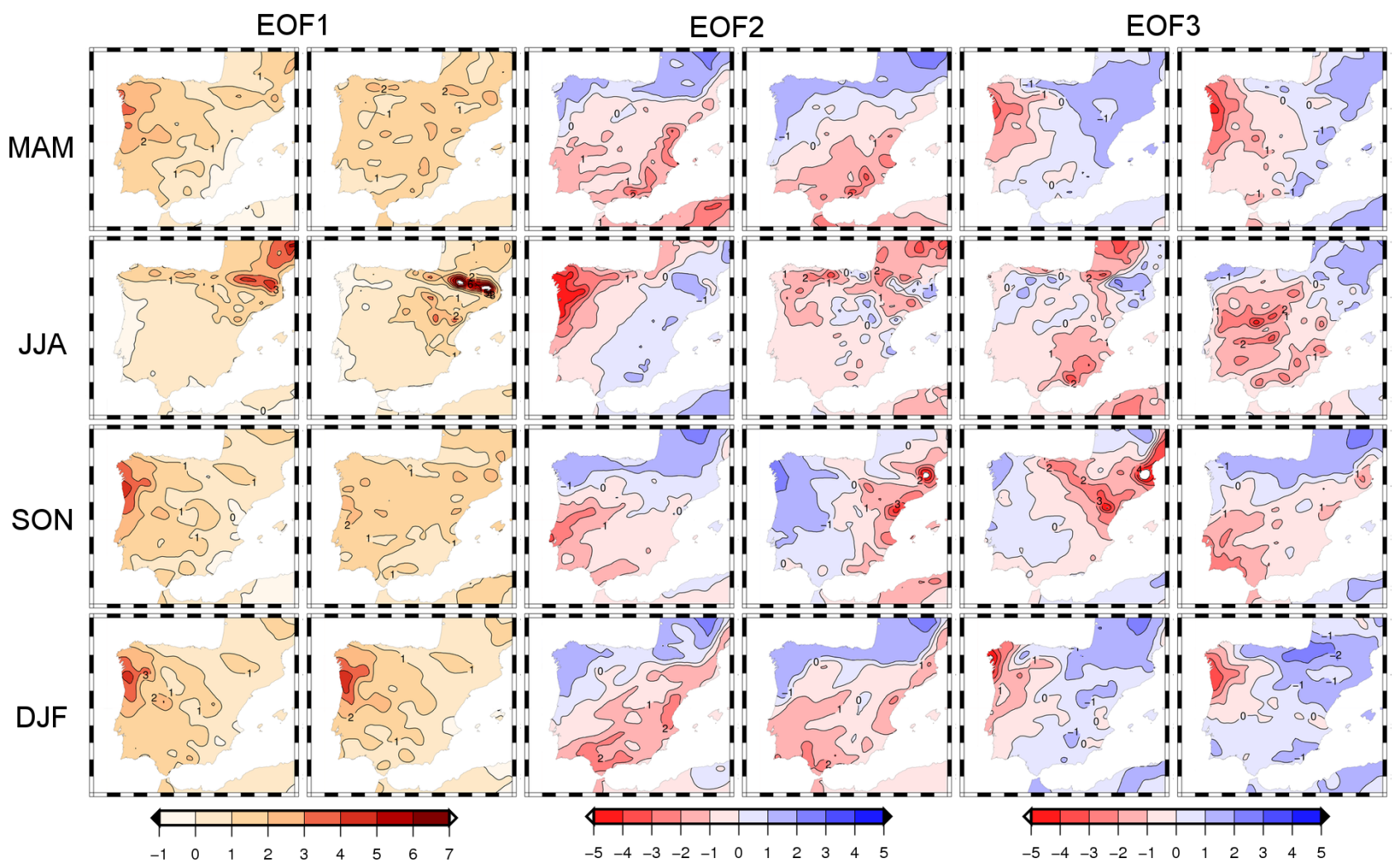

Fig. 9. Normalised EOF patterns obtained from the seasonal mean series of precipitation for the period 1961-1990 in the simulations ECHO-G + MM5 (left) and ERA40 + MM5 (right).

forced by the advective flow. Note that in autumn the ordering of the second and third EOF seem to be swapped in both experiments. This is not surprising since the percentage of variance explained by these two EOFs for ERA40 + MM5 is pretty similar: 13.42 and 13.30 respectively (see Table 2).

Overall, there is a relative good agreement between the EOF patterns in both simulations. In particular the EOF patterns varies coherently through the seasons and along the EOF hierarchy. The SAT patterns follow an annual cycle similar to the one found previously in an ensemble of climate change projections (Gómez-Navarro et al., 2010). Regarding precipitation, similar agreement between simulations is found in winter, although several differences linked to the overestimation of the zonal flow, appear in summer. Hence, not only mean values and variability of the climatologies developed by MM5 when coupled to ECHO-G are similar to ERA40, but also the main variability modes (with some deficiencies). This supports the idea that the dynamical downscaling of ECHO-G simulation is able to capture the main features of the present climate of the IP. Thus, provided that the boundary conditions of the AOGCM are relatively good, it can be expected that the RCM will also be able to reproduce the actual features of past climates. It is important to highlight that the dynamical downscaling process is able to display spatial gradients at regional scale that the AOGCM can not. For instance, precipitation in the Northwest of the IP is dominated by the zonal flow from the Atlantic ocean, whereas its effect in the South-Eastern areas is weaker. These details, which are due to regional features and are implicitly included in the proxy reconstructions, can barely be simulated by a coarse resolution AOGCM.

\subsection{Regional climate and synoptic conditions: NAO}

The North Atlantic Oscillation (NAO) is a well known variability pattern in the winter sea level pressure (SLP) field affecting the climate of the North Atlantic-European sector. In particular, it strongly affects the precipitation events in winter in most parts of the IP (Trigo et al., 2004). To ascertain that the relationship between the NAO and the precipitation over the IP is robust in the observed climate, we have calculated the correlation map between a NAO index and the winter precipitation for the IP in the period 1950-1990. The NAO index is defined here as the standardised series of the principal component associated to the leading EOF of the mean SLP in winter in the geographical box $70^{\circ} \mathrm{W}$ to $50^{\circ} \mathrm{E}$ and from $20^{\circ} \mathrm{N}$ to $75^{\circ} \mathrm{N}$. To perform these calculations we have used the E-OBS data base of precipitation over the IP (Haylock et al., 2008) and the NCEP reanalysis (Kalnay et al., 1996) for SLP. The result is depicted in the left map of Fig. 10. The 


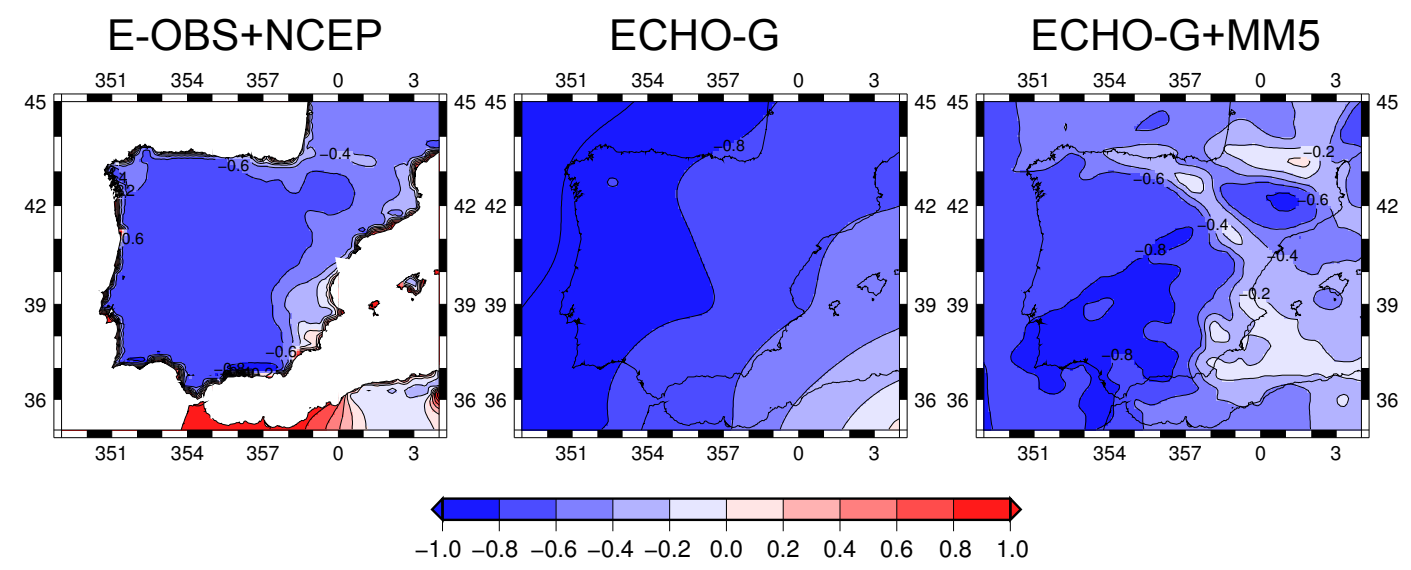

Fig. 10. Correlation maps between NAO and winter precipitation over the IP as reproduced by ECHO-G (left), ECHO-G + MM5 (centre), and a combination of reanalysis for SLP and observations for precipitation (right). The NAO index is defined in the main text.

correlation between this index and the winter precipitation is quite strong, reaching values of -0.6 over most of the domain. It is nevertheless less strong in the eastern parts, where the influence of the Atlantic flow in the precipitation regime is weaker.

We have investigated the link between the NAO variations and the precipitation within the models. The central map of Fig. 10 depicts the result of same calculations as above but using the ECHO-G model for the same period. The model is capable of simulating this relationship, although it overestimates its importance (the correlation is below -0.8 in the Northwestern half of the IP). The precipitation in the Southeast seems to be also too strongly driven by this circulation mode, a feature which is not very realistic. The map on the right of the same figure shows the result when MM5 is used to simulate the climate over the IP. In this case, we have calculated the NAO index using the data simulated by the AOGCM, since the former area lies outside the domain of our regional simulation and the regional model introduces no significant modifications with respect to the driving model in this variable. Apart from the clear gain in spatial resolution, in this case the precipitation regime is quite different, and is not so strongly driven by the Atlantic flow (correlation -0.6 over most areas, although it reaches -0.8 in some areas in the Southwest), approximating the simulation to the observations. In good agreement with them, the RCM is able to simulate areas in the Southeast where the precipitation is very weakly driven by NAO, and overall the spatial correlation between left and right maps over land points is 0.7 . Nevertheless, compared to observations, the RCM results are more affected by important orographic features like the Pyrenees or the Iberic System, around the centre of the Iberian Peninsula. Since there is evidence of the reasonable skill of RCMs in complex orography areas such as the Alps (Frei et al., 2003), a plausible explanation for theses differences could be that the observational data base is less reliable over mountains, since precipitation measures in these areas are especially scarce, and they are therefore interpolated from data of nearby meteorological stations.

Thus, Fig. 10 clearly illustrates another aspect of the added value by the RCM simulation: its capability to realistically simulate the physical connections between the large-scale systems simulated by the driving model and the response of the local climate to them. Nevertheless, and according to the comments made before, the temporal evolution of these circulation modes in the AOGCM is not directly driven by the external forcings, but it is strongly affected by internal variability. This has deep impacts in the evolution of precipitation over the IP (Luterbacher et al., 2010). For this reason, we should not expect in general a good agreement between NAO variations in the model and in the reconstructions. We will further discuss this aspect when comparing the model results with some reconstructions of the climate in the next sections.

\section{Climate in the last 1000 years in the IP}

In the former section we evaluated the added value of the RCM simulation and illustrated how the dynamical downscaling is able to narrow the differences between ECHO$\mathrm{G}$ and ERA40 for a reference period. In this section we highlight the main features of the simulation performed with MM5 coupled to ECHO-G for the 1001-1990 period. We also perform some comparisons with proxy-based reconstructions.

\subsection{AOGCM versus RCM simulation}

Figure 11 gives an overall idea of the path followed of the simulation. Upper panels represent the 31-years running mean of the SAT anomalies for winter and summer with respect to the period 1900-1990. Red lines correspond to ECHO-G and blue lines to ECHO-G + MM5. The series are averaged over an area which covers the entire IP, including 

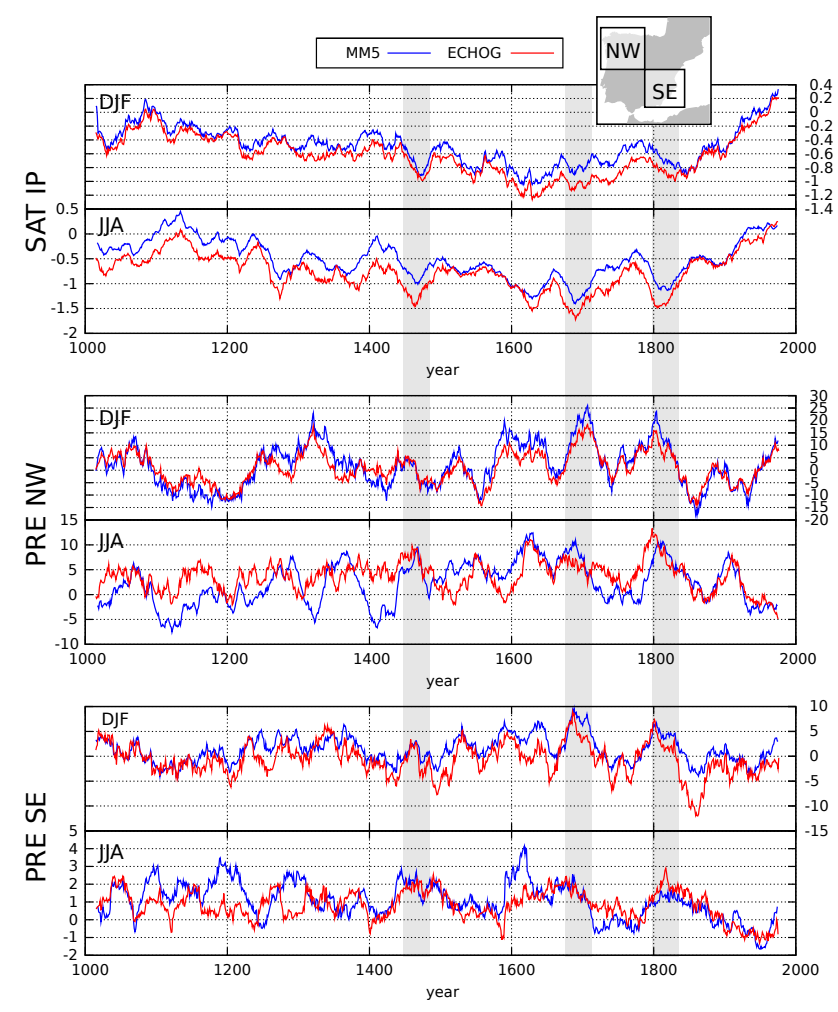

Fig. 11. Anomaly series of SAT over the IP (upper panel, in ${ }^{\circ} \mathrm{C}$ ) Northwest precipitation (middle panel, in $\mathrm{mm} / \mathrm{month}$ ) and Southeast precipitation (lower panel, in $\mathrm{mm} \mathrm{month}^{-1}$ ) in winter (DJF) and summer (JJA), respectively. The NW and SE subdomains are represented in the grey map in the top-right corner of the figure. Red line represents the series for ECHO-G and blue line for ECHO$\mathrm{G}+\mathrm{MM} 5$. Ocean grid-cells are also included in the calculations. Anomalies are calculated with respect to the period 1900-1990, and a 31-years running mean have been applied to all series. Grey bars indicate three cold periods discussed in the main text.

ocean grid-cells. The middle panel represents the same information but regarding the precipitation anomaly for the Northwest of the IP, whereas the lower panel refers to the evolution of the precipitation in the Southeast. We split the precipitation series into two areas because the precipitation regime and amount are quite different in these two areas, as shown in Fig. 4. However, SAT evolution is not so heterogeneous, and so we consider just the simple spatial average. We include ocean grid-cells to be consistent in the figure, since ECHO$\mathrm{G}$ does not include any land grid-cell in the southeastern area. In this figure, the high correlation between the variations in both simulations for all seasons is apparent. This is not surprising since the AOGCM drives the RCM simulation. There are nevertheless some differences which will be discussed below. In general, discrepancies in the simulations should not be sought in the domain-averaged series but in their high resolution spatial structure, as illustrated later.

In the SAT series (upper panels of Fig. 11), we may identify a warm initial condition, followed by a cold period which roughly covers $1400-1850$, and ends with a warm trend which continues until the end of the simulations. These warm/cold periods match well with respective historical periods that are relatively well documented in other parts of the world and commonly denominated as the Medieval Warm Period and the LIA. The final warming trend from roughly 1850 to the end of the simulation is simultaneous with the rise of the concentration of GHGs as prescribed in the model run (Fig. 1). The RCM tends to follow ECHO-G more weakly in summer, as we can clearly identify around 1120, 1410, and 1740 in this season.

Looking at higher frequency variability, several marked minima in the SAT anomalies can be identified around the periods $1430-1450,1600-1620,1675-1710$, and 1800-1830, in general more noticeably in summer. Some of these cold periods match fairly well known historical periods, like the Spörer minimum (1420-1440), the Maunder minimum (1675-1710), and the Dalton minimum (1800-1830), which are marked with a grey band in the figure. Furthermore, they seem to be directly driven by variations in the external forcing (Fig. 1). For this reason, we use hereafter these denominations to denote the anomalies in temperature and precipitation simulated by the model which coincide in time with these anomalies in the forcing conditions. Note that the model also simulates a cold period around 1620 that is not driven by any of the external forcings. This aspect will be further commented on in the final discussion in the context of internal variability of climate models. Interestingly, there are some minima that can be identified in all seasons, such as the Spörer minimum, whereas others, like the Maunder minimum, can hardly be identified in winter. This implies that the amplitude of the annual cycle is strongly reduced in the Maunder minimum, but not in other cold periods, and this suggests that the physical mechanism under different cold periods could be very different.

Precipitation series show in general larger differences between the global and regional simulations. As in the case of SAT, this is especially noticeable in summer. The reason for this is that whereas winter precipitation in the IP is largely dominated by large scale systems (see the next section), and hence by the boundary conditions that drive the RCM, summer precipitation in the IP is more convective. As illustrated by Fernández et al. (2007), the effect of the higher spatial resolution and the different physical parametrisation of both models play an important role in this precipitation regime, and thus explains the larger differences in summer. There are also important differences between the North West and the South East of the IP, one of the most important being the large difference in the variability of the series (which is linked to the mean precipitation). It is not so easy to identify in these series the low frequency signal of the LIA, but there exists an overall negative relationship with the SAT series, like a strong winter precipitation maximum around the Maunder Minimum and the opposite trends of both variables in summer over the last century. The temporal correlation of the 


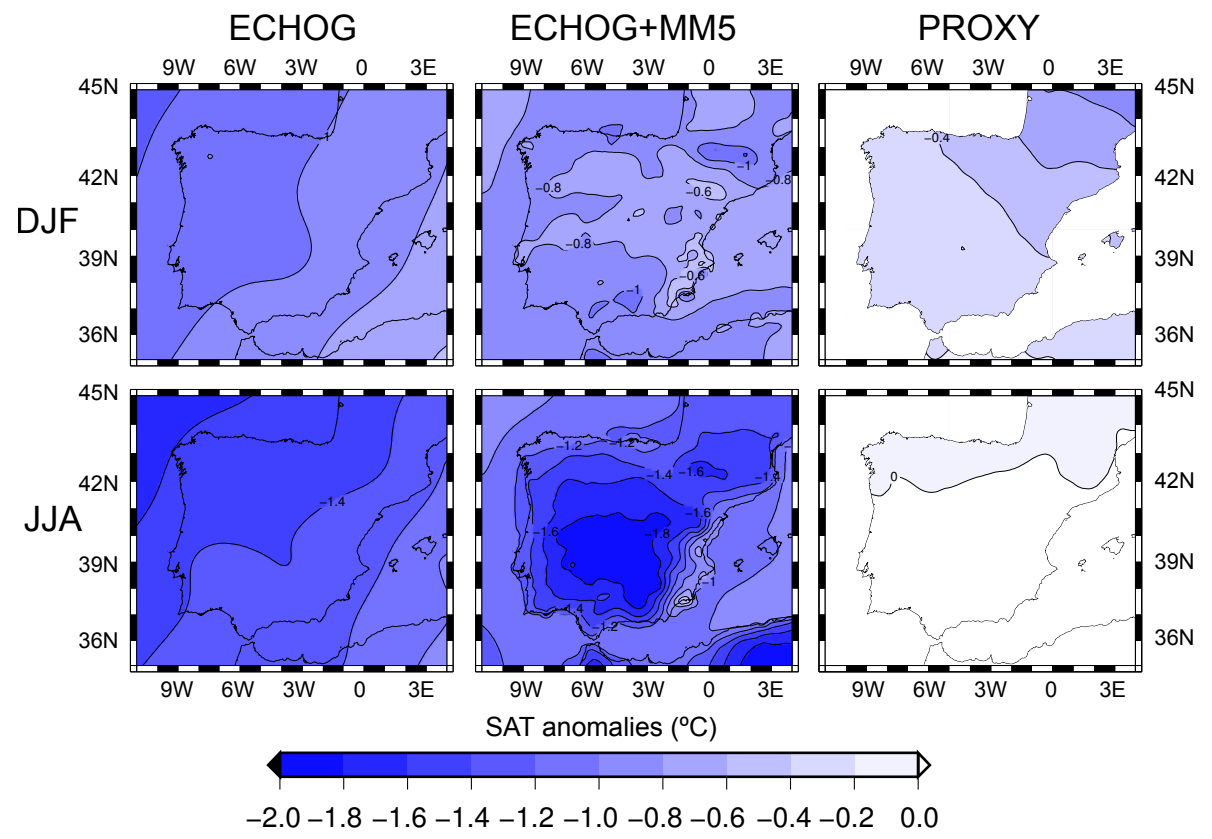

Fig. 12. SAT temperature anomalies for winter (top row) and summer (bottom row) in the 1671-1700 period with respect to 1900-1990. The figure shows the results for ECHO-G (left), ECHO-G + MM5 (centre), and the SAT reconstruction (right).

31-years running mean series of SAT and precipitation, both averaged over the whole IP, is -0.16 in winter and -0.83 in summer. Using a bootstrap method, the confidence interval for the correlation at the $95 \%$ level was found to be \pm 0.39 and \pm 0.50 for both seasons, respectively. Hence, although the winter anti correlation between precipitation and SAT can be due to chance, the summer case seems to be statistically significant. In fact, the relationship between drier and warmer conditions in the dry season has been reported in several climate change projections for the 21 th century in the Mediterranean area (Giorgi and Bi, 2005), so our findings are coherent with these results, and reinforce some conclusions of these studies in the context of past climates. In winter, the negative correlation between these variables is weaker, partly due to the positive tendency they share in the last century.

As discussed above, some differences in the climatologies developed by the RCM and the AOGCM simulations are found at regional scales. For illustration, Fig. 12 depicts the summer and winter SAT anomalies in the Maunder minimum with respect to the 1900-1990 period as simulated by ECHO-G (left) and ECHO-G + MM5 (centre) and reconstructed by Luterbacher et al. (2004) (right). In this section we focus on the differences between the AOGCM and the RCM. Although it is shown in the figure, comparison with proxy-based reconstructions is performed in the next section. The spatial average of the anomalies in both simulations is similar, as can be appreciated in Fig. 11. Furthermore, anomalies are overall larger in summer than in winter in both simulations. However, the spatial distribution of the coldest areas is different. In the ECHO-G simulation they are located outside of the IP, decreasing to the Southeast towards the Mediterranean Sea. The spatial structure of the anomalies is similar in both seasons. In the RCM simulation the coldest areas are rather located in the centre of the peninsula in summer, and in the higher areas in winter. It is interesting to note that similar spatial patterns, with the same seasonal cycle, were found for the warming patterns for the 21 st century in regional climate change projections for the same area (Gómez-Navarro et al., 2010). Differences between the two simulations could be related to the coarse topography, as the south half part of the IP is defined as ocean, as can be seen in Fig. 2. Similar differences are apparent for the rest of seasons and for the other cold periods (not shown).

Similarly, Fig. 13 shows the same information as Fig. 12 but for precipitation anomalies: winter and summer anomalies in the Maunder minimum for ECHO-G, ECHOG + MM5 and reconstructed by Pauling et al. (2006). ECHO$\mathrm{G}$ simulates a homogeneous increase in precipitation about $20 \%$ for most of the IP in summer, and slightly higher in the West of the IP in winter. However, although the RCM also simulates an average increase of precipitation in both seasons (see Fig. 11), its shape is very different. In fact, the high resolution model simulates a strong increase in precipitation in some areas of the Southwest of the IP. However, there are some areas in the Southeast where there is no increase of precipitation. This behaviour is inverted in autumn for the same period, where a strong increase of precipitation is observed in the Southeast in the MM5 simulation which is not present in ECHO-G (not shown). 


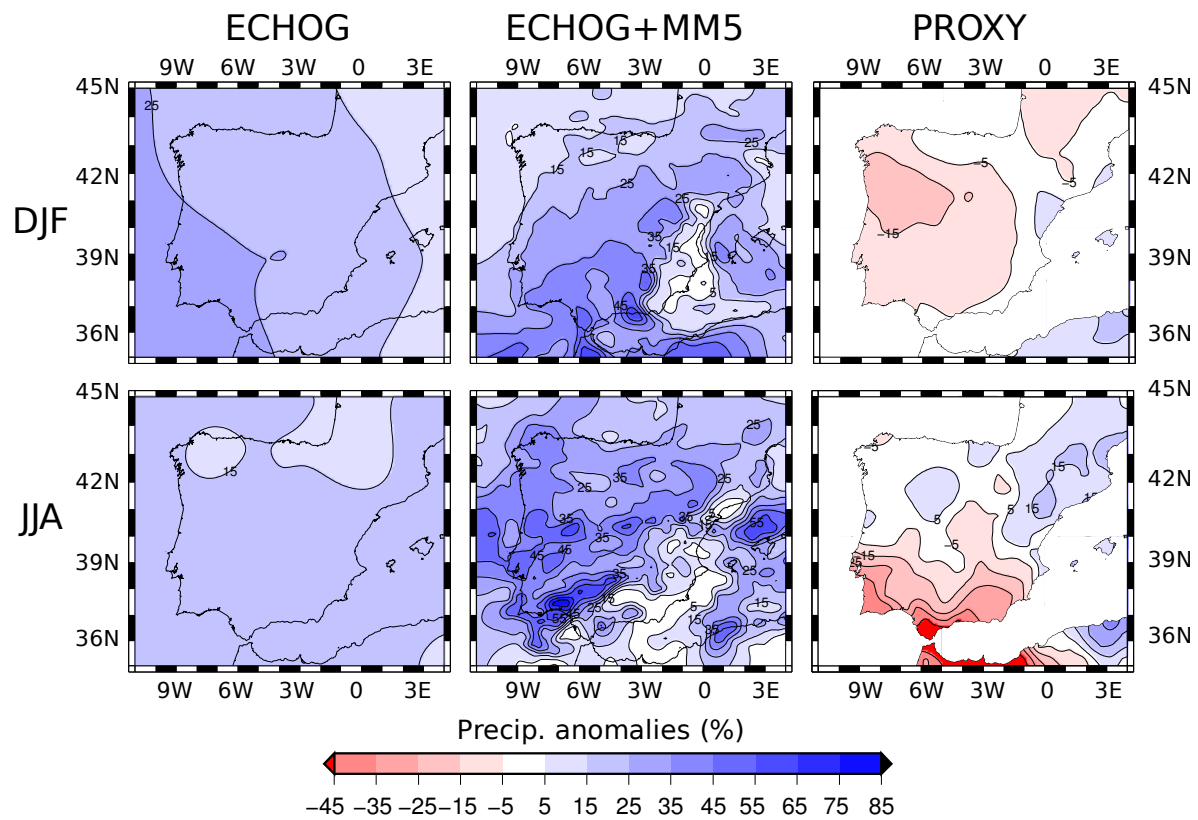

Fig. 13. Precipitation anomalies for winter (top row) and summer (bottom row) in the 1671-1700 period with respect to 1900-1990. The figure shows the results for ECHO-G (left), ECHO-G + MM5 (centre), and the precipitation reconstruction (right).

In general, the low-frequency evolution of the RCM is dominated by the AOGCM, as is clearly illustrated in Fig. 11. Nevertheless, the added value of the RCM appears in the high-frequency domain. Top (bottom) row in Fig. 14 shows the correlation between the annual series of SAT (precipitation) in every each grid point and the corresponding mean value for the IP domain in ECHO-G (left) and MM5 (right). The series have been previously filtered through a high-pass filter which only allows frequencies higher than $0.3 \mathrm{yr}^{-1}$. This filtering prevents the slow variations in the climate to increase the correlation among grid points in different locations of the domain. In SAT, ECHO-G is hardly able to decipher any differences between several areas within the IP. On the contrary, MM5 reduces the correlation between the mean behaviour of the IP and some areas in the Southeast, reaching values below 0.8 . The corresponding maps in the low-frequency domain (not shown) are identically equal to 1 , further indicating the strong influence of the driving model in the low frequency evolution of the RCM. In precipitation MM5 introduces larger differences. Although the correlation for precipitation series in ECHO-G is lower than for SAT, it displays a strongly homogeneous behaviour. Nevertheless, in the MM5 simulation there are areas near the Mediterranean Sea with evolution uncorrelated with the mean behaviour. The correlation pattern seems to be related to the main mountain systems (see Fig. 2), which suggests that the improvement is, to a great extent, introduced by the more realistic orography.

The differences in the shape of anomalies of SAT and precipitation in both simulations are partly due to the higher spatial resolution of the RCM, which allows it to develop
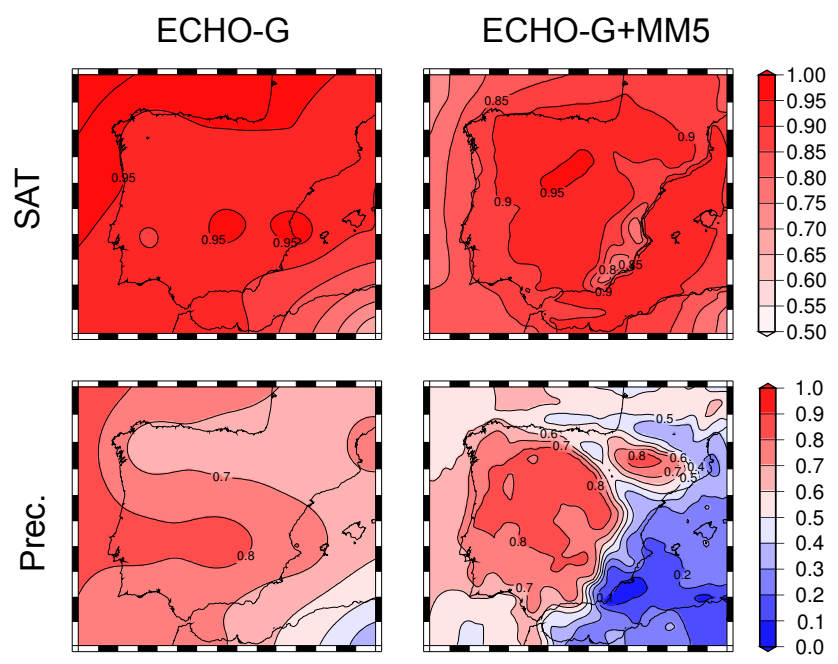

Fig. 14. Top row: correlation between annual series of SAT in each grid point and the domain-averaged series corresponding to the ECHO-G (left column) and ECHO-G + MM5 (right column) simulations. Bottom row: the same calculation for precipitation. The correlation is calculated for the period 1001-1990, and the series have been low-frequency filtered to remove frequencies below $0.3 \mathrm{yr}^{-1}$.

more realistic local dynamics. In addition, in large areas such as our outer domain, the regional model is able to generate its own synoptic scale circulation, which is slightly different from that of the AOGCM. The modification of this circulation may importantly affect the regional climate. These 
regional differences further illustrate how the RCM, although driven by the AOGCM, is able to develop quite different climatologies at local scales (Déqué et al., 2005). Nevertheless, it is important to note that the improvements introduced by the RCM depend strongly on the variable of interest. In SAT, the AOGCM strongly drives the regional model, although it is still able to introduce some differences in the highfrequency. In precipitation, the RCM introduces large departures from the driving model, in part due to the strong impact of high-resolution orography in the precipitation events. The improvements introduced by the RCM may impact the inter comparisons between proxy-based reconstructions and model simulations, as the AOGCMs are not able to simulate local flow patterns which strongly modulate observed climate in a given area.

\subsection{Comparison with proxy-based reconstructions}

Figure 15 shows the evolution of the anomalies in SAT (upper panel), Northwest precipitation (middle panel), and Southeast precipitation (lower panel) for the ECHOG + MM5 simulation (blue line) and the corresponding reconstructions of SAT (Luterbacher et al., 2004) and precipitation (Pauling et al., 2006). As in Fig. 11, the anomalies are calculated with respect to the period 1900-1990, but in this case ocean grid-cells of the model have not been considered to be consistent with the reconstructions. SAT winter series variability is similar, but it is higher in the simulation: standard deviation 0.27 and 0.20 in the model and the reconstruction, respectively. There is also a clear positive trend at the end of the period in both series, although in the model it begins around 50 years earlier. In general, the trends are larger in the model, which could be related to the fact that the model forcings do not include anthropogenic aerosols. In summer, reconstructions show less variability than the model ( 0.17 and 0.46 , respectively), although the final trends are similar. The main difference is that, in both seasons, the model is between 0.5 and $1{ }^{\circ} \mathrm{C}$ colder than the reconstructions. The temporal agreement between model and reconstructions in the cold periods simulated by the model is not very good. In the columns 2 and 3 of Fig. 12 we compare the winter and summer SAT anomalies for the Maunder minimum. Although the sign of the anomaly is the same, the reconstruction does not present the strong cold period in summer SAT as simulated by both models. There is a better agreement in winter in the intensity of this anomaly, although its spatial structure is also different.

Precipitation anomaly tends to be larger in the model than in the reconstructions in both seasons in the Northwest (see series in the middle panel in Fig. 15). Variability of the 31-years running mean series of winter precipitation for the model and the reconstruction in the period $1500-1990$ is similar for both the Nortwestern (standard deviation 8.1 and $6.3 \mathrm{~mm} \mathrm{month}^{-1}$ in the model and in the reconstruction, respectively) and Southestern areas (standard deviation 3.0 and
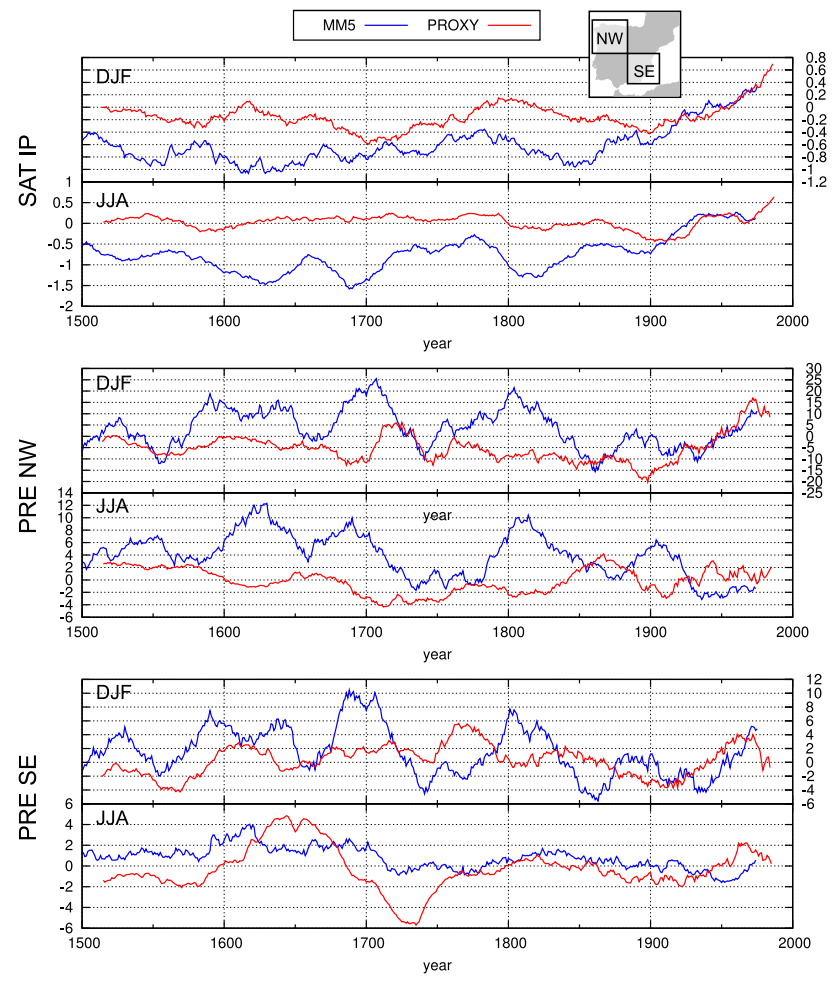

Fig. 15. Anomaly series of SAT over the IP (upper panel, in ${ }^{\circ} \mathrm{C}$ ) Northwest precipitation (middle panel, in $\mathrm{mm} / \mathrm{month}$ ) and Southeast precipitation (lower panel, in $\mathrm{mm} \mathrm{month}^{-1}$ ) in winter (DJF) and summer (JJA), respectively. The NW and SE subdomains are represented in the grey map in the top-right corner of the figure. Red line represents the series for the reconstructions and blue line for ECHO-G + MM5. Ocean grid-cells are excluded in the calculations. Anomalies are calculated with respect to the 1900-1990 period, and a 31-years running mean have been applied to all series.

$2.2 \mathrm{~mm} \mathrm{month}^{-1}$ in the model and in the reconstruction, respectively). There is also a good agreement in the upward final trend in the wet areas, where the precipitation variations are larger. Summer precipitation variability is nevertheless larger in the model in the wet area and lower in the dry area. The temporal agreement between the model and the reconstruction is also low. To illustrate these differences, in columns 2 and 3 of Fig. 13 we compare the winter and summer precipitation anomalies for the Maunder minimum (1671-1700). The spatial structure of precipitation anomalies do not agree, and the mean values are also different (spatial-averaged anomalies of $-4 \%$ and $22 \%$ in winter precipitation in the reconstructions and the model, respectively). In particular, the reconstruction shows a strong dry anomaly in the South in summer (decrease of precipitation up to $90 \%$ ) that is opposite to the result obtained with the model.

However, with the information we have to date it is not easy to assess whether this mismatch is due to deficiencies of the reconstructions, of the model, or of both. In addition, 
it is also possible and even probable that part of the variations in precipitation is caused internally and is not related to the external forcing. In that case, model and reconstructions should not necessarily agree. We have explored this possibility through the relations between NAO and precipitation. In Sect. 3.4 we showed that MM5 is able to develop a realistic link between NAO and precipitation events over the IP. Figure 16a shows the precipitation anomaly series for the IP domain together with the NAO index simulated by ECHOG + MM5 for the whole simulated period. We can appreciate how the Maunder minimum is characterised by the positive precipitation anomaly indicated above, and it can now be linked to the strong minimum in the NAO index. A similar behaviour can be found around the Dalton minimum. In fact, there is a clear anti-correlation between both series during all the simulation (the correlation coefficient between the NAO index and precipitation for the whole millennium is -0.84).

Hence, according to Fig. 16a, the positive precipitation anomaly during the Maunder minimum seems to be driven by a weaker NAO phase within the model. This allows us to test the precipitation reconstructions over the IP against independent reconstructions of the NAO index. The argument is as follows: we do not expect in general a good temporal agreement between the NAO index in the model and the reconstructions, since this circulation mode is strongly dominated by internal variability. Nevertheless, the model is complex enough to realistically simulate the physical mechanisms which link the evolution of NAO and precipitation in the IP. Thus, if the NAO evolution in a given period in the model is by chance in phase with the evolution of the actual climate, the precipitation pattern developed by the model in that period would be a reliable version of the precipitation in the actual climate, and then it could be compared against reconstructions.

Figure 16b shows a NAO reconstruction performed by Luterbacher et al. (2002) (green line), together with the Pauling et al. (2006) precipitation series (blue line). These series show a realistic anti-correlation behaviour, which is not surprising since they share some proxies and to some extent the NAO reconstructions include precipitation proxies. In these reconstructions there is not such low NAO phase driving the strong positive precipitation anomalies, as it was observed in the simulation. Nevertheless, there are large uncertainties in the evolution of NAO during the last millennium. To illustrate this, the recent NAO reconstruction by Trouet et al. (2009) is shown in the red line in the same figure. The Trouet et al. (2009) reconstructions is based on two proxy indicators, one of them also used by Luterbacher et al. (2002). However, there are large mismatches between them. In fact, the Trouet et al. (2009) record is in slightly better agreement with the model evolution. In particular, it exhibits a strong NAO index in the Medieval Warm Period which is weakened in the LIA. During the Maunder Minimum it reaches a relative minimum, although it is not one of the strongest in the record, as is the case of the simulation. Nevertheless, the agreement is

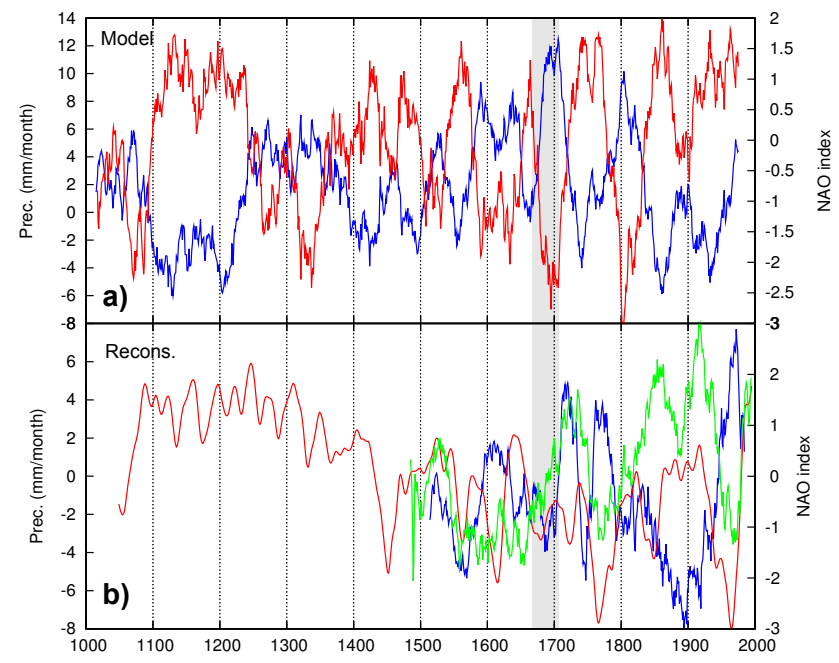

Fig. 16. (a) NAO index (red line) and precipitation (blue line) as simulated by ECHO-G + MM5 during the last millennium. (b) NAO index as reconstructed by Luterbacher et al. (2002) (green line), by Trouet et al. (2009) (red line), and Pauling et al. (2006) precipitation series (blue line). All anomalies are calculated with respect to the period 1900-1990 and averaged for the IP. Green line has been smoothed through a low-pass filter, likewise the rest of the series have been smoothed through a running mean of 31 years. Grey bar indicates the Maunder Minimum period discussed in the text.

low in general and rather inhomogeneous along the millennium.

Concluding, Fig. 16 clearly illustrates how, although NAO has a strong impact in precipitation events in the IP, there are still large uncertainties in its evolution during the last millennium. Neither the model nor the different reconstructions agree in general. Although the model is able to develop a realistic link between NAO and precipitation, the evolution of this circulation mode is to a great extent dominated by variability, which makes the comparison with proxies difficult. In addition, since the proxy-based precipitation records discussed here show some skill (the Reduction of Error for the IP presented by Pauling et al. (2006) is positive, i.e. past winter precipitation estimates are better than climatology), to explain the differences between these reconstructions and the model will require a deeper analysis.

\section{Summary and conclusions}

The high spatial resolution simulation described in the former sections represents an added value to previous paleosimulation performed with ECHO-G (Zorita et al., 2005, and references herein). By means of a comparison with a dynamical downscaling performed with reanalysis data, MM5 was shown to be able to significantly improve the skill of ECHO-G in reproducing the observed climate in the IP in the 1961-1990 period. In particular, differences between 
climate developed in ERA40 and ECHO-G are larger than those for the corresponding regionalized data sets. Thus, the RCM narrows the differences between these two simulations. Furthermore, MM5 is also able to narrow differences between the climate developed by ECHO-G and the E-OBS data base. This supports the idea that the regionalization of an AOGCM paleosimulation may improve the quality of this model at regional scales. These improvements pertain to the modification of the seasonal variability, which is modified by MM5, bringing it closer to observations in the reference period. Nevertheless, there are some differences in the simulations with respect to the observations in the reference period which are attributable to the inherent internal variability of the model, thus hampering the assessment of the skill of the model.

External forcings seem to have an important role in the simulation. There is a series of minima and maxima in the effective TSI that can be linked with corresponding cold/warm periods, and that match several known historical periods. In particular, the models are able to simulate the LIA and the Medieval Optimum as a direct response to radiation forcing. On the other hand, in the last 150 years of the 20th century there is an increase in temperature which seems to be linked to the continuous rise of GHGs concentrations characteristic of the industrial period. There are nevertheless some cold minima that can not be explained by the external forcings, for instance in the period 1600-1620. This minimum seems to be caused by the internal characteristic variability of the AOGCM. If this is the case, this introduces an important uncertainty factor, since the amplitude of the internal variability could in principle even explain all the simulated minimum at the regional scales. This amplitude could be better estimated downscaling the control run with ECHO-G, using an ensemble of simulations using different AOGCMs, or even using the same AOGCM with different initial conditions. This avenue will be explored in future studies.

Although domain-averaged values of SAT and precipitation in the RCM simulation are very similar to those of the AOGCM in the same area, some important differences appear at regional scales. These can be more clearly found in the high-frequency evolution of the regional climate, or in the shape and intensity of SAT and precipitation anomaly patterns in a given period. For example, MM5 simulates a precipitation anomaly pattern in the Maunder minimum which is qualitatively different to that simulated by ECHO-G. In general, the differences introduced by the RCM are less noticeable for SAT than for precipitation, which is more strongly modified by the coarse resolution of the AOGCM. These differences introduced by the RCM may have an important impact in the inter comparison exercises between proxy-based reconstructions and model simulations.

We have compared the results of the model simulation with the SAT and precipitation reconstruction of Luterbacher et al. (2004) and Pauling et al. (2006) over the Iberian Peninsula, respectively. The model results tend to be colder than the reconstruction, more noticeably in the LIA. Winter SAT variability is similar, although the model overestimates it. However, in summer the reconstruction clearly depicts less variability. There is a relatively good agreement in the final trend in the 20th century. Precipitation series show similar variability in the model and in the reconstructions, although the correlation between both is low. In particular, the positive anomaly in precipitation simulated by the model does not seem to reproduce the reconstruction in the past centuries.

Overall, the high-resolution information added by MM5 to the ECHO-G simulation does not tend to narrow differences between the models and the reconstructions, especially for precipitation. Instead, MM5 is able to add high-resolution details to the AOGCM simulation, but following in general terms the path of the AOGCM which drives the simulation, especially in winter when the regional climate within the considered domain is more strongly governed by synoptic conditions. It is important to note that the RCM should narrow differences with reconstructions only in the case that the RCM significantly reduces errors of ECHO-G in the last millennium, and also in the case that the reconstructions employed here realistically represent the actual evolution of the past climate. Hence, we find that one of these conditions (or maybe both) is not met. In any case, the added value of the RCM is that it is able to simulate a physically consistent climate that takes into account the characteristics due to high resolution orographic features over the Iberian Peninsula. This simulated high-resolution, physically consistent, climate can be used to test some aspect of the reconstructions, such as variability of the series (which is a measure of the sensitivity of the climate to external forcings and its internal variability at regional scale), as well as test physical relationships between variables such as the link between large circulation modes and local events. These kinds of questions can hardly be addressed within an AOGCM.

An important part of the disagreement between the simulated and reconstructed precipitation can be attributed to internal variability in the model through the evolution of NAO in the model, although a complete explanation will require further analysis. This disagreement is important because it can be carried further to place confidence in the simulations of future climate in the Iberian Peninsula and the Mediterranean region in general. Climate projections indicate a strong decrease of precipitation in this region (Giorgi and $\mathrm{Bi}, 2005)$ with a high level of agreement across the suite of IPCC models (IPCC, 2007). The ECHO-G model, also included in the IPCC suite, also simulates strong decreases of winter precipitation in the future under increasing concentrations of greenhouse gases. If the sign of the simulated precipitation changes disagrees with that of the reconstructions, the confidence placed on the future projections at regional scales would be compromised. However, it is important to note that this argument depends on the kind of response of the climate to external forcing. In climate change projections, the magnitude of the external forcing lies outside anything that 
has been seen in the last millennium, and the response to the climate to this forcing can not be expected to be linear in general.

As future work, further intercomparisons between the RCM simulation and newer proxy-based reconstructions that are being developed at this moment in the IP will be performed in order to validate more aspects of the simulation. Furthermore, more regional simulations will be carried out using different AOGCM simulations. The aim of these ensemble of simulations is to evaluate the importance of the internal variability of the AOGCM driving the simulation, and trying to separate its effect from the impact of the external forcings.

Acknowledgements. This work was funded by the Spanish Ministry of the Environment (project SALVA-SINOVAS, Ref. 200800050083542) and the Spanish Ministry of Science and Technology (project SPECMORE-CGL2008-06558-C02-02/CLI). The authors also gratefully acknowledge the funding from the Euro-Mediterranean Institute of Water (IEA). We acknowledge the E-OBS data set from the EU-FP6 project ENSEMBLES (http://ensembles-eu.metoffice.com) and the data providers in the ECA \& D project (http://eca.knmi.nl). J. J. Gómez-Navarro thanks the Spanish Ministry of Education for his Doctoral scholarship (AP2006-04100). We also thank Jürg Luterbacher for the interesting insights about uncertainties in proxy reconstructions, which improved the final version of this paper.

Edited by: V. Rath

\section{References}

Ammann, C. M., Joos, F., Schimel, D. S., Otto-Bliesner, B. L., and Tomas, R. A.: Solar influence on climate during the past millennium: Results from transient simulations with the NCAR Climate System Model, P. Natl. Acad. Sci. USA, 104, 3713-3718, doi:10.1073/pnas.0605064103, 2007.

Bradley, R. S. and Jones, P. D.: "Little Ice Age" summer temperature variations: their nature and relevance to recent global warming trends, Holocene, 3, 367-376, doi:10.1177/095968369300300409, 1993.

Chen, F. and Dudhia, J.: Coupling an Advanced Land SurfaceHydrology Model with the Penn State-NCAR MM5 Modeling System, Part I: Model Implementation and Sensitivity, Mon. Weather Rev., 129, 569-585, 2001a.

Chen, F. and Dudhia, J.: Coupling an Advanced Land SurfaceHydrology Model with the Penn State-NCAR MM5 Modeling System, Part II: Preliminary Model Validation, Mon. Weather Rev., 129, 587-604, 2001b.

Crowley, T.: Causes of climate change over the past 1000 years, Science, 289, 270, 2000.

Déqué, M., Jones, R., Wild, M., Giorgi, F., Christensen, J., Hassell, D., Vidale, P., Rockel, B., Jacob, D., Kjellstrom, E., de Castro, M., Kucharski, F., and van den Hurk, B.: Global high resolution versus Limited Area Model climate change projections over Europe: quantifying confidence level from PRUDENCE results, Clim. Dynam., 25, 653-670, doi:10.1007/s00382-005-0052-1, 2005.
Déqué, M., Rowell, D. P., Lüthi, D., Giorgi, F., Christensen, J. H., Rockel, B., Jacob, D., Kjellström, E., de Castro, M., and van den Hurk, B.: An intercomparison of regional climate simulations for Europe: assessing uncertainties in model projections, Climatic Change, 81, 53-70, doi:10.1007/s10584-006-9228-x, 2007.

Dudhia, J.: Numerical study of convection observed during the winter monsoon experiment using a mesoscale two-dimensional model, J. Atmos. Sci., 46, 3077-3107, 1989.

Dudhia, J.: A Nonhydrostatic Version of the Penn StateNCAR Mesoscale Model: Validation Tests and Simulation of an Atlantic Cyclone and Cold Front, Mon. Weather Rev., 121, 1493-1513, 1993.

Fernández, J., Montávez, J. P., Saenz, J., González-Rouco, J. F., and Zorita, E.: Sensitivity of the MM5 mesoscale model to physical parameterizations for regional climate studies: Annual cycle, J. Geophys. Res.-Atmos., 112, D04101, doi:10.1029/2005JD006649, 2007.

Font-Tullot, I.: Climatología de España y Portugal, Ediciones Universidad de Salamanca, Salamanca, 2nd edition, 2000.

Frei, C., Christensen, J. H., Déqué, M., Jacob, D., Jones, R. G., and Vidale, P. L.: Daily precipitation statistics in regional climate models: Evaluation and intercomparison for the European Alps, J. Geophys. Res., 108(D3), 4124, doi:10.1029/2002JD002287, 2003.

Giorgi, F. and Bi, X.: Updated regional precipitation and temperature changes for the 21 st century from ensembles of recent AOGCM simulations, Geophys. Res. Lett., 32, L21715, doi:10.1029/2005GL024288, 2005.

Gleckler, P. J., Taylor, K. E., and Doutriaux, C.: Performance metrics for climate models, J. Geophys. Res., 113, D06104, doi:10.1029/2007JD008972, 2008.

Gómez-Navarro, J. J., Montávez, J. P., Jiménez-Guerrero, P., Jerez, S., Garcia-Valero, J. A., and González-Rouco, J. F.: Warming patterns in regional climate change projections over the Iberian Peninsula, Meteorol. Zeit., 19, 275-285, 2010.

González-Rouco, F., von Storch, H., and Zorita, E.: Deep soil temperature as proxy for surface air-temperature in a coupled model simulation of the last thousand years, Geophys. Res. Lett., 30(21), 2116, doi:10.1029/2003GL018264, 2003.

González-Rouco, J. F., Beltrami, H., Zorita, E., and Stevens, M. B.: Borehole climatology: a discussion based on contributions from climate modeling, Clim. Past, 5, 97-127, doi:10.5194/cp-5-972009, 2009.

Graham, L. P., Olsson, J., Kjellström, E., Rosberg, J., Hellström, S.-S., and Berndtsson, R.: Simulating river flow to the Baltic Sea from climate simulations over the past millennium, 5th Study Conference on BALTEX, Kuressaare, Estonia, 4-8 June 2007, Boreal Environ. Res., 14, 173-182, 2009.

Grell, G. A.: Prognostic evaluation of assumptions used by cumulus parameterizations, Mon. Weather Rev., 121, 764-787, 1993.

Grell, G. A., Dudhia, J., and Stauffer, D. R.: A description of the fifth-generation Penn State/NCAR Mesoscale Model (MM5), Tech. Rep. NCAR/TN-398+STR, National Center for Atmospheric Research, Colorado, 1994.

Haylock, M. R., Hofstra, N., Tank, A. M. G. K., Klok, E. J., Jones, P. D., and New, M.: A European daily highresolution gridded data set of surface temperature and precipitation for 1950-2006, J. Geophys. Res.-Atmos., 113, D20119, doi:10.1029/2008JD010201, 2008. 
Hofstra, N., Haylock, M., New, M., and Jones, P. D.: Testing EOBS European high-resolution gridded data set of daily precipitation and surface temperature, J. Geophys. Res., 114, D21101, doi:10.1029/2009JD011799, 2009.

Hong, S. Y. and Pan, H. L.: Nonlocal boundary layer vertical diffusion in a medium-range forecast model, Mon. Weather Rev., 124, 2322-2339, 1996.

Hostetler, S., Bartlein, P., Clark, P., Small, E., and Solomon, A.: Simulated influences of Lake Agassiz on the climate of central North America 11,000 years ago, Nature, 405, 334-337, 2000.

Huybers, P. and Curry, W.: Links between annual, Milankovitch and continuum temperature variability, Nature, 441, 329-332, doi:10.1038/nature04745, 2006.

IPCC: Climate Change 2007: The Physical Science Basis: Contribution of Working Group I to the Fourth Assessment Report of the Intergovernmental Panel on Climate Change, Cambridge University Press, New York, 2007.

Jerez, S., Montávez, J. P., Gómez-Navarro, J. J., Jiménez-Guerrero, P., Jiménez, J. M., and González-Rouco, J. F.: Temperature sensitivity to the land-surface model in MM5 climate simulations over the Iberian Peninsula, Meteorol. Z., 19, 1-12, 2010.

Jones, P., Osborn, T., and Briffa, K.: The evolution of climate over the last millennium, Science, 292, 662-667, 2001.

Jones, P. D., Briffa, K. R., Osborn, T. J., Lough, J. M., van Ommen, T. D., Vinther, B. M., Lutherbacher, J., Wahl, E. R., Zwiers, F. W., Mann, M. E., Schmidt, G. A., Ammann, C. M., Buckley, B. M., Cobb, K. M., Esper, J., Goosse, H., Graham, N., Jansen, E., Kiefer, T., Kull, C., Kuettel, M., Mosley-Thompson, E., Overpeck, J. T., Riedwyl, N., Schulz, M., Tudhope, A. W., Villalba, R., Wanner, H., Wolff, E., and Xoplaki, E.: Highresolution palaeoclimatology of the last millennium: a review of current status and future prospects, Holocene, 19, 3-49, doi:10.1177/0959683608098952, 2009.

Jungclaus, J. H., Lorenz, S. J., Timmreck, C., Reick, C. H., Brovkin, V., Six, K., Segschneider, J., Giorgetta, M. A., Crowley, T. J., Pongratz, J., Krivova, N. A., Vieira, L. E., Solanki, S. K., Klocke, D., Botzet, M., Esch, M., Gayler, V., Haak, H., Raddatz, T. J., Roeckner, E., Schnur, R., Widmann, H., Claussen, M., Stevens, B., and Marotzke, J.: Climate and carbon-cycle variability over the last millennium, Clim. Past, 6, 723-737, doi:10.5194/cp-6723-2010, 2010.

Kalnay, E., Kanamitsu, M., Kistler, R., Collins, W., Deaven, D., Gandin, L., Iredell, M., Saha, S., White, G., Woollen, J., Zhu, Y., Leetmaa, A., and Reynolds, R.: The NCEP/NCAR 40-Year Reanalysis Project, B. Am. Meteorol. Soc., 77, 437-470, 1996.

Kjellström, E., Brandefelt, J., Näslund, J.-O., Smith, B., Strandberg, G., Voelker, A. H. L., and Wohlfarth, B.: Simulated climate conditions in Europe during the Marine Isotope Stage 3 stadial, Boreas, 39, 436-456, doi:10.1111/j.1502-3885.2010.00143.x, 2010

Kleidon, A., Fraedrich, K., and Heimann, M.: A green planet versus a desert world: estimating the maximum effect of vegetation on the land surface climate, Climatic Change, 44, 471-493, 2000.

Krivova, N. A. and Solanki, S. K.: Models of solar irradiance variations: Current status, J. Astrophys. Astron., 29, 151-158, 2008.

Legutke, S. and Voss, R.: The Hamburg atmosphere-ocean coupled circulation model ECHO-G, Tech. rep., DKRZ, Hamburg, Germany, 1999.
Luterbacher, J., Xoplaki, E., Dietrich, D., Jones, P., Davies, T., Portis, D., González-Rouco, J., Von Storch, H., Gyalistras, D., Casty, C., and Wanner, H.: Extending North Atlantic oscillation reconstructions back to 1500, Atmos. Sci. Lett., 2, 114-124, 2002.

Luterbacher, J., Dietrich, D., Xoplaki, E., Grosjean, M., and Wanner, H.: European seasonal and annual temperature variability, trends, and extremes since 1500, Science, 303, 1499-1503, 2004.

Luterbacher, J., Gómez-Navarro, J. J., Montávez, J. P., GonzálezRouco, J. F., Werner, J. G., and Zorita, E.: Comparison of century-long regional climate experiments with proxy based climate reconstructions over the Iberian Peninsula (Invited), in: AGU Fall Meeting Abstracts, vol. 1, PP53A-04 pp., 2010.

Mann, M. E., Zhang, Z., Hughes, M. K., Bradley, R. S., Miller, S. K., Rutherford, S., and Ni, F.: Proxy-based reconstructions of hemispheric and global surface temperature variations over the past two millennia, P. Natl. Acad. Sci. USA, 105, 13252-13257, doi:10.1073/pnas.0805721105, 2008.

Mlawer, E. J., Taubman, S. J., Brown, P. D., Iacono, M. J., and Clough, S. A.: Radiative transfer for inhomogeneous atmospheres: RRTM, a validated correlated- model for the longwave, J. Geophys. Res., 102, 16663-16682, 1997.

Montávez, J. P., Fernández, J., González-Rouco, J. F., Saenz, J., Zorita, E., and Valero, F.: Climate change projections over the Iberian Peninsula, in: V Asamblea Hispano Portuguesa de geodesia y geofísica, Ministerio de Medio Ambiente, Sevilla, 2006.

Pauling, A., Luterbacher, J., Casty, C., and Wanner, H.: Five hundred years of gridded high-resolution precipitation reconstructions over Europe and the connection to large-scale circulation , Clim. Dynam., 26, 387-405, doi:10.1007/s00382-005-0090-8, 2006.

Renssen, H., Isarin, R., Jacob, D., Podzun, R., and Vandenberghe, J.: Simulation of the Younger Dryas climate in Europe using a regional climate model nested in an AGCM: preliminary results, Workshop on Rapid Climatic Warming at the End of the Last Glacial - Palaeodata Analysis and Climate Modeling, Haarlem, The Netherlands, 22- 24 February 2000, Global Planet. Change, 30, 41-57, 2001.

Stevens, M., González-Rouco, J., and Beltrami, H.: North american climate of the last millennium: underground temperatures and model comparison, J. Geophys. Res.-Earth, 113, F01008, doi:10.1029/2006JF000705, 2008.

Strandberg, G., Brandefelt, J., Kjellström, E., and Smith, B.: Highresolution regional simulation of last glacial maximum climate in Europe, Tellus A, 63, 107-125, 2011.

Swingedouw, D., Terray, L., Cassou, C., Voldoire, A., Salas-Mélia, D., and Servonnat, J.: Natural forcing of climate during the last millennium: fingerprint of solar variability. Low frequency solar forcing and NAO, Clim. Dynam., doi:10.1007/s00382-0100803-5, in press, 2010.

Taylor, K.: Summarizing multiple aspects of model performance in a single diagram., J. Geophys. Res.-Atmos., 106, 7183-7192, 2001.

Tett, S. F. B., Betts, R., Crowley, T. J., Gregory, J., Johns, T. C., Jones, A., Osborn, T. J., Oestroem, E., Roberts, D. L., and Woodage, M. J.: The impact of natural and anthropogenic forcings on climate and hydrology since 1550, Clim. Dynam., 28 , 3-34, 2007. 
Trigo, R., Pozo-Vazquez, D., Osborn, T., Castro-Diez, Y., Gamiz-Fortis, S., and Esteban-Parra, M.: North Atlantic oscillation influence on precipitation, river flow and water resources in the Iberian peninsula, Int. J. Climatol., 24, 925-944, doi:10.1002/joc.1048, 2004.

Trouet, V., Esper, J., Graham, N. E., Baker, A., Scourse, J. D., and Frank, D. C.: Persistent positive Norh Atlantic Oscillation model dominated the Medieval Climate Anomaly, Science, 324, 78-80, doi:10.1126/science.1166349, 2009.

Ulbrich, U., Leckebusch, G., and Pinto, J.: Extra-tropical cyclones in the present and future climate: a review, Theor. Appl. Climatol., 96, 117-131, 2009.

Uppala, S., Kallberg, P., Simmons, A., Andrae, U., Bechtold, V., Fiorino, M., Gibson, J., Haseler, J., Hernandez, A., Kelly, G., Li, X., Onogi, K., Saarinen, S., Sokka, N., Allan, R., Andersson, E., Arpe, K., Balmaseda, M., Beljaars, A., Van De Berg, L., Bidlot, J., Bormann, N., Caires, S., Chevallier, F., Dethof, A., Dragosavac, M., Fisher, M., Fuentes, M., Hagemann, S., Holm, E., Hoskins, B., Isaksen, L., Janssen, P., Jenne, R., McNally, A., Mahfouf, J., Morcrette, J., Rayner, N., Saunders, R., Simon, P., Sterl, A., Trenberth, K., Untch, A., Vasiljevic, D., Viterbo, P., and Woollen, J.: The ERA-40 re-analysis, Q. J. Roy. Meteor. Soc., 131, 2961-3012, doi:10.1256/qj.04.176, 2005. van der Linden, P. and Mitchell, J. F. B.: ENSEMBLES: Climate Change and its Impacts: Summary of research and results from the ENSEMBLES projec, Met Office Hadley Centre, FitzRoy Road, Exeter, UK, 2009.

von Storch, H. and Zwiers, F.: Statistical Analysis in Climate Research, Cambridge University Press, 1999.

Yoshimori, E. M., Stocker, T. F., Raible, C., and Renold, M.: Externally forced and internal variability in ensemble climate simulations of the Maunder Minimum, J. Climate, 18, 4253-4270, 2005.

Zorita, E., González-Rouco, J. F., von Storch, H., Montávez, J. P., and Valero, F.: Natural and anthropogenic modes of surface temperature variations in the last thousand years, Geophys. Res. Lett., 32, 755-762, 2005.

Zorita, E., Moberg, A., Leijonhufvud, L., Wilson, R., Brázdil, R., Dobrovolný, P., Luterbacher, J., Böhm, R., Pfister, C., Riemann, D., Glaser, R., Söderberg, J., and González-Rouco, F.: European temperature records of the past five centuries based on documentary information compared to climate simulations, Climatic Change, 101, 143-168, doi:10.1007/s10584-010-9824-7, 2010. 